\title{
Migratory properties of pulmonary dendritic cells are determined by their developmental lineage
}

\author{
H Nakano ${ }^{1}$, JE Burgents ${ }^{1}, \mathrm{~K}$ Nakano ${ }^{1}$, GS Whitehead ${ }^{1}$, C Cheong ${ }^{2}$, CD Bortner ${ }^{3}$ and DN Cook ${ }^{1}$
}

The chemokine receptor, CCR7, directs the migration of dendritic cells (DCs) from peripheral tissue to draining lymph nodes (LNs). However, it is unknown whether all pulmonary DCs possess migratory potential. Using novel Ccr $7^{\text {gfp }}$ reporter mice, we found that $C c r 7$ is expressed in $C D 103^{+}$and a CD1 $4^{\text {med/lo }}$ subset of CD11 $b^{\text {hi }}$ classical (c)DCs but not in monocyte-derived (mo)DCs, including Ly- $6 C^{\text {hi }} C D 11 b^{\text {hi }}$ inflammatory DCs and CD1 $4{ }^{\text {hi }} C D 11 b^{\text {hi }}$ DCs. Consequently, CDCs migrated to lung-draining LNs but moDCs did not. Mice lacking the chemokine receptor, CCR2, also lacked inflammatory DCs in the lung after lipopolysaccharide inhalation but retained normal levels of migratory DCs. Conversely, the lungs of fms-like tyrosine kinase 3 ligand (Flt3L)-deficient mice lacked cDCs but retained moDCs, which were functionally mature but did not express $\mathrm{Ccr} 7$ and were uniformly non-migratory. Thus, the migratory properties of pulmonary DCs are determined by their developmental lineage.

\section{INTRODUCTION}

Dendritic cells (DCs) initiate adaptive immune responses by processing antigens and presenting them to $\mathrm{T}$ cells. In the lung, the actions of DCs determine whether inhaled antigens elicit effector or tolerogenic immune responses. ${ }^{2}$ DC migration from the lung to draining lymph nodes (LNs) proceeds at low levels during steady-state conditions, but the rate and volume of that migration is increased following exposure to pro-inflammatory stimuli. ${ }^{3,4}$ However, some antigen-bearing DCs remain in the lung for prolonged periods, ${ }^{5-7}$ and selective depletion of DCs during the challenge phase of murine models of asthma abrogates allergic responses. ${ }^{8,9}$ These data suggest that DC retention in the lung might be important to activate memory $\mathrm{T}$ cells arriving in the lung. It is unknown, however, whether all DCs that are exposed to appropriate stimuli have the capacity to migrate to draining LNs. One possibility is that some lung DCs reside in an anatomical position that shields them from stimuli that would otherwise promote migration. Alternatively, DCs might become migratory on a stochastic basis that ensures an appropriate distribution of DCs in the lung and draining LNs. A third possibility is that some DCs lack the capacity for migration.

Recent studies have shown that pulmonary DCs are not homogeneous but are comprised of multiple subsets that can be distinguished phenotypically by their display levels of various cell surface markers. As in other non-lymphoid tissues, DCs in the lung are comprised of two major classical $\mathrm{cDC}$ subsets: CD $11 c^{\text {high }}{ }^{(\text {hi }} \mathrm{CD} 11 b^{\text {hi }} \mathrm{CD} 103^{-}$DCs and $\mathrm{CD} 11 \mathrm{c}^{\text {hi }} \mathrm{CD} 11 \mathrm{~b}^{\text {low }}$ ${ }^{(\mathrm{lo})} \mathrm{CD} 103^{+}{ }^{+} \mathrm{DCs},{ }^{10}$ often referred to as $\mathrm{CD} 11 \mathrm{~b}^{\mathrm{hi}}$ and $\mathrm{CD} 103^{+}$ DCs, respectively. $\mathrm{CD} 103^{+}$DCs are tightly associated with the respiratory epithelium and extend processes into the lumen of the airway. ${ }^{10}$ These cells represent the major DC subset in the lung for cross-presenting antigens to $\mathrm{CD}^{+} \mathrm{T}$ cells, ${ }^{11}$ promoting viral clearance ${ }^{12}$ and directing $\mathrm{T}$ helper type 2 (Th2) responses to inhaled allergens. ${ }^{13} \mathrm{CD} 11 \mathrm{~b}^{\text {hi }}$ DCs reside beneath the epithelium and can produce large amounts of chemokines. ${ }^{14}$ In addition to CD $11 b^{\text {hi }}$ DCs that are present in the lung during homeostasis, $\mathrm{Ly}-6 \mathrm{C}^{+} \mathrm{CD} 11 \mathrm{c}^{\text {int }} \mathrm{CD} 11 \mathrm{~b}^{\mathrm{hi}}$ monocyte-derived DCs (moDCs) are rapidly recruited to the lung during inflammation. ${ }^{15}$ moDCs also display high levels of CD14, which distinguishes them from CD11b ${ }^{\text {hi }}$ cDCs. ${ }^{16}$

The migration of DCs to draining LNs is guided by interactions between the chemokine receptor, CCR7, and its ligands, CCL19 and CCL21, which are produced in the lymphatic vessels and in T-cell areas of LNs. ${ }^{17-19}$ Many $\mathrm{CD}_{103}{ }^{+} \mathrm{DCs}$ display CCR7 and are dependent on this receptor for their migration to lung-draining mediastinal (m)LNs. ${ }^{20}$

\footnotetext{
${ }^{1}$ Laboratory of Respiratory Biology, National Institute of Environmental Health Sciences, NIH, Research Triangle Park, North Carolina, USA. ${ }^{2}$ Laboratory of Cellular Physiology and Immunology and Chris Browne Center for Immunology and Immune Diseases, The Rockefeller University, New York, New York, USA and ${ }^{3}$ Laboratory of Signal Transduction, Division of Intramural Research, National Institute of Environmental Health Sciences, NIH, Research Triangle Park, North Carolina, USA. Correspondence: DN Cook (cookd@niehs.nih.gov)
} 
Consequently, $\mathrm{CD}_{103}{ }^{+}$DCs are virtually absent in mLNs of $\mathrm{Ccr} 7^{-1-}$ mice. However, CD11b $\mathrm{b}^{\text {hi }}$ DCs can be found in mLNs of these mice, albeit at reduced levels compared with those of wildtype mice, ${ }^{13,20}$ suggesting that $\mathrm{CD} 11 \mathrm{~b}{ }^{\mathrm{hi}}$ DCs can gain access to mLNs by both CCR7-dependent and -independent pathways. Other studies have confirmed that under some circumstances, $\mathrm{CD} 11 \mathrm{~b}^{\text {hi }}$ DCs can migrate from the lung to mLNs, ${ }^{21,22}$ but it is unclear whether all CD11b ${ }^{\text {hi }}$ DCs have this potential.

DCs are derived from monocytes and the common DC precursor $(\mathrm{CDP})^{23,24}$ The latter can differentiate into either plasmacytoid DCs or pre-DCs ${ }^{25,26}$. Recent studies have suggested that $\mathrm{CD}_{103}{ }^{+}$DCs are derived exclusively from CDPs and pre-DCs via a developmental pathway dependent on interactions between fms-like tyrosine kinase 3 (FLT3) and its ligand (FLT3L) ${ }^{27,28}$ However, CD11b ${ }^{\text {hi }}$ DCs in mucosal tissue can develop from monocytes, which do not require FLT3 or FLT3L for their differentiation into DCs. ${ }^{24}$ Blood-borne monocytes are comprised of two distinct populations, expressing high levels of the CCR2 and CX3CR1, respectively, ${ }^{29}$ and both of these populations can give rise to lung DCs, even during homeostatic conditions. ${ }^{30}$ Thus, the lung contains CDPderived classical CD103 ${ }^{+}$and CD11b ${ }^{\text {hi }}$ DCs (cDCs), as well as $\mathrm{CD} 11 \mathrm{~b}^{\text {hi }}$ moDCs. Whether CD11bi $\mathrm{bCs}$ in the lung that arise from these alternative developmental pathways possess different migratory capacities and functions is unknown. Here, we report that in the lung, FLT3-dependent $\mathrm{CD} 103^{+} \mathrm{cDCs}$ and $\mathrm{CD} 11 \mathrm{~b}{ }^{\mathrm{hi}} \mathrm{cDCs}$ are migratory, whereas moDCs are non-migratory. These differences have important implications with regard to the initiation of primary T-cell responses in mLNs and stimulation of secondary T-cell responses in the lung.

\section{RESULTS}

\section{$\mathrm{CD}_{103}{ }^{+} \mathrm{DCs}$ and a subpopulation of $\mathrm{CD} 11 \mathrm{~b}^{\mathrm{hi}} \mathrm{DCs}$ are migratory}

DCs in the lung were identified as low-density CD11c ${ }^{+} \mathrm{I}_{-} \mathrm{A}^{+}$ autofluorescence ${ }^{\text {lo }}$ cells (see Supplementary Figure S1a online). Although alveolar macrophages are also CD $11 c^{+}, 31,32$ their autofluorescence and display of Siglec-F distinguishes them from DCs (see Supplementary Figure S1b online). ${ }^{33}$ Accordingly, we used autofluorescence to gate out macrophages from our analysis of pulmonary DCs. In mLNs, DCs were identified as $\mathrm{CD} 11 \mathrm{c}^{+} \mathrm{I}-\mathrm{A}^{+} \mathrm{CD} 3^{\text {lo }} \mathrm{CD} 19^{\text {lo }}$ cells. We confirmed that $\mathrm{CD} 11 \mathrm{~b}^{\text {hi }}$ DCs and $\mathrm{CD}_{103}{ }^{+} \mathrm{DCs}$ are the major DC subsets in the lungs of untreated mice, with $\mathrm{CD}_{103}{ }^{+}$DCs being slightly more abundant (Figure 1a). Under steady-state conditions, most DCs in lung-draining mLNs were CD11bi ${ }^{\text {hi }}$, with very few $\mathrm{CD}_{103}{ }^{+}$DCs (Figure 1b), in agreement with previous reports. ${ }^{3}$

DC migration from the lung to $\mathrm{mLNs}$ is increased following inhalation of pro-inflammatory stimuli, such as lipopolysaccharide (LPS) ${ }^{34}$ We found that the total number of CD $11 b^{\text {hi }}$ DCs in the lung increased markedly during the 24-h period after instillation of ovalbumin (OVA) mixed with LPS (OVA/ LPS), whereas the number of $\mathrm{CD}_{103}{ }^{+}$DCs decreased (Figure 1a), suggesting that some of the latter cells had migrated to mLNs. Analysis of mLNs revealed that both
CD $11 b^{\text {hi }}$ DCs and CD $103^{+}$DCs were dramatically increased after OVA/LPS treatment (Figure 1b). The latter DC subset was increased 10-fold over the very low levels seen in mLNs of untreated mice.

Although DCs ferry antigen from peripheral tissue to draining LNs, some soluble proteins such as OVA can be carried rapidly in the lymph from the lung to mLNs, where they are taken up by mLN DCs. ${ }^{20}$ Thus, in studies of lung DC migration, it is critically important to distinguish between antigen-bearing DCs arriving from the lung and $\mathrm{mLN}$-resident DCs that acquire soluble antigens while in the LN. Previous studies have shown that inhaled carboxyfluorescein diacetate succinimidyl ester (CFSE) stains lung-resident DCs, thereby allowing these cells to be identified after their migration to mLNs. ${ }^{20}$ However, instillation of CFSE causes airway inflammation, ${ }^{35}$ which confounds studies of DC trafficking during homeostasis. For this reason, we tested the utility of an alternative fluorescent dye, PKH26 (PKH) ${ }^{36}$ and found that it readily stained pulmonary DCs. No DCs in mLNs were stained by PKH by $4 \mathrm{~h}$ after PKH instillation, indicating that unlike OVA, PKH is not passively carried in the lymph to LNs. This allowed us to track the migration of $\mathrm{PKH}$-stained pulmonary DCs to mLNs (Figure 1c and see Supplementary Figures S1c,d online). Moreover, PKH did not induce airway inflammation, whereas CFSE did (see Supplementary Figure S1e online). Based on these results, we concluded that PKH was an appropriate dye to study pulmonary DC migration.

Instillation of OVA/LPS into the airway markedly increased the number of $\mathrm{PKH}^{+}$DCs in mLNs compared with the number seen under steady-state conditions (Figures 1c,d). The vast majority of these migratory DCs were $\mathrm{CD}_{103}{ }^{+}$, although some $\mathrm{PKH}^{+}$CD11b ${ }^{\text {hi }}$ DCs were also seen, and their numbers were also significantly increased by OVA/LPS. Most $\mathrm{PKH}^{+}$DCs of both subsets displayed high levels of major histocompatibility complex (MHC) class II in agreement with a previous report showing that migratory DCs are MHC class II ${ }^{\text {hi. }}$. However, we found that some $\mathrm{PKH}^{+} \mathrm{CD} 11 \mathrm{~b}$ hi DCs displayed moderate levels of this molecule (see Supplementary Figure S1f online). Taken together, these data suggest that $\mathrm{CD}_{103}{ }^{+}$DCs are the major migratory DC subset in the lung, although a subpopulation of CD11b ${ }^{\text {hi }}$ DCs also possesses migratory activity.

\section{CD11b ${ }^{\text {hi }}$ DC migration from the lung to mLNs is CCR7- dependent}

$\mathrm{CD}_{103}{ }^{+}$DCs are virtually absent in $\mathrm{mLNs}$ of $\mathrm{Ccr} 7^{--}$mice, although some CD11b $b^{\text {hi }}$ DCs can be found (Figure 1e). ${ }^{13,20}$ This indicates that some CD11b ${ }^{\text {hi }}$ DCs can gain access to mLNs by both CCR7-dependent and -independent pathways. To determine whether $\mathrm{CD} 11 \mathrm{~b}{ }^{\text {hi }}$ DCs can migrate from the lung to mLNs in a CCR7-independent manner, we used PKH staining of DCs to analyze their migration in wild-type and $\mathrm{Crr}^{1 /-}$ mice. In mLNs of wild-type mice, most migratory $\mathrm{PKH}^{+}$DCs were $\mathrm{CD}_{103}{ }^{+}$, although some $\mathrm{PKH}^{+} \mathrm{CD} 11 \mathrm{~b}^{\text {hi }}$ DCs were also seen. However, mLNs of $\mathrm{C} c r 7^{-1-}$ mice contained almost no $\mathrm{PKH}^{+}$ DCs of either subset (Figure 1f). Thus, migration of lung 
a

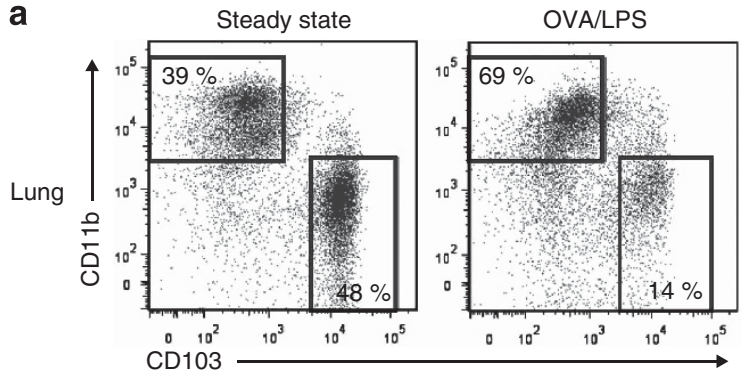

b

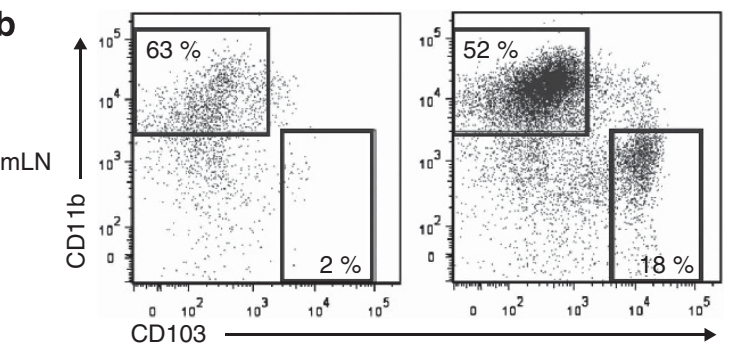

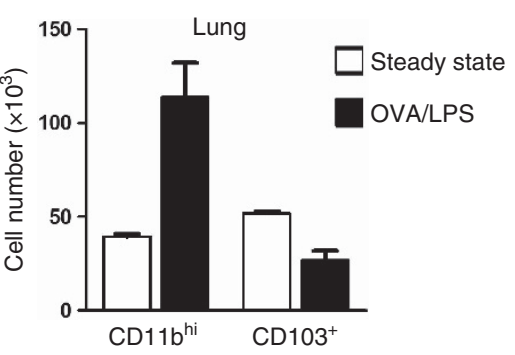

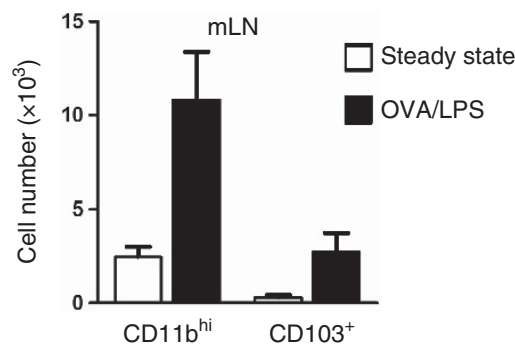

C

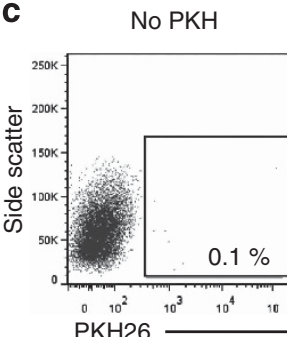

PKH (steady state)

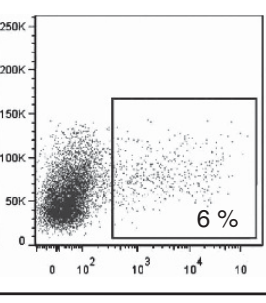

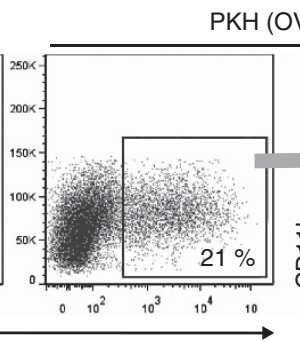

OVA/LPS)

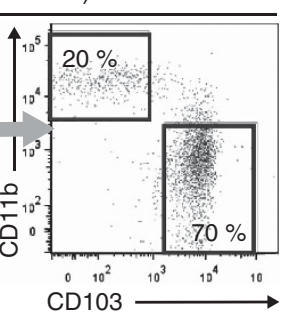

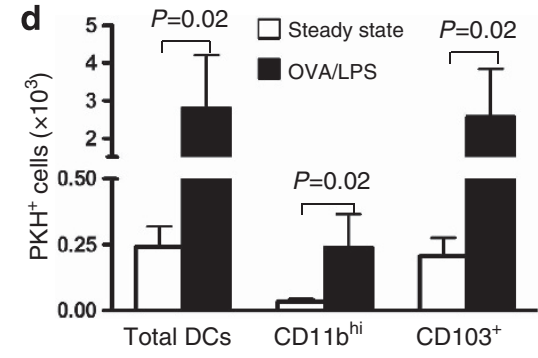

e

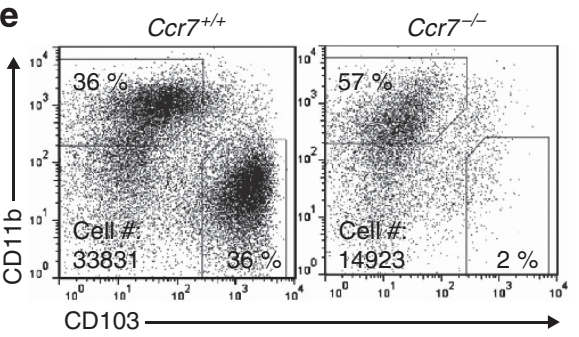

f

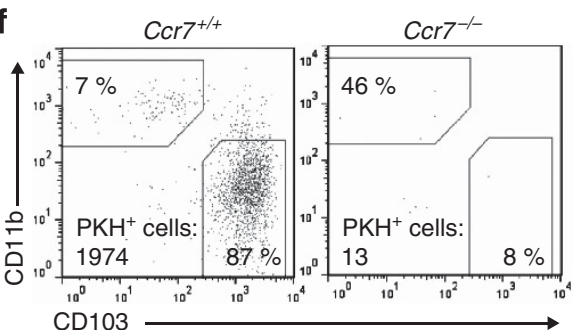

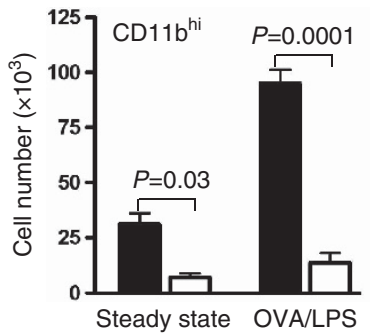
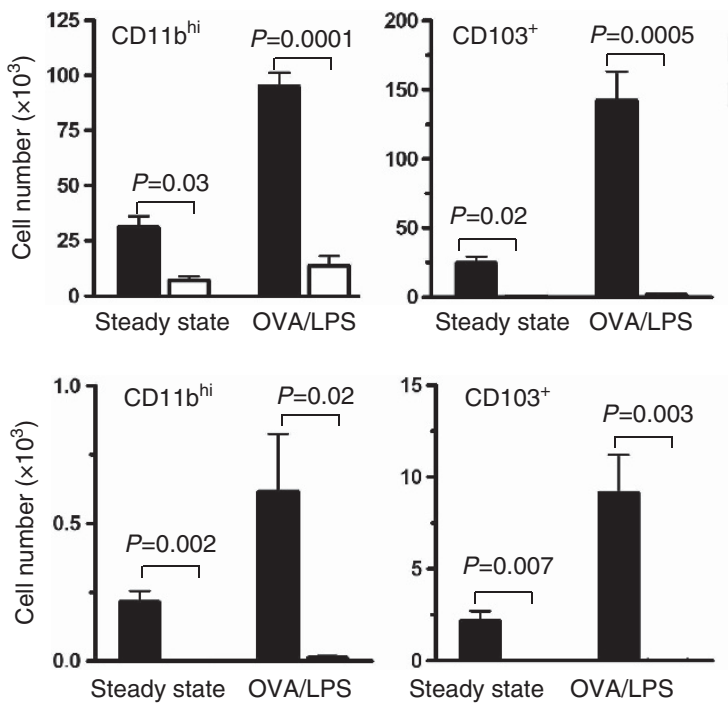

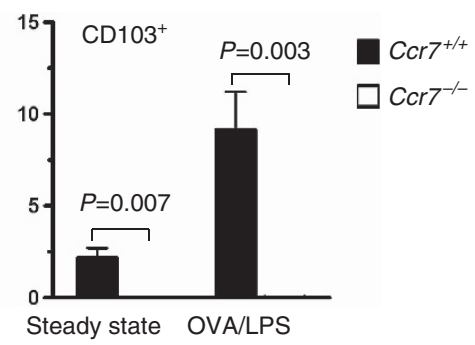

Figure $1 \mathrm{CD} 103^{+}$dendritic cells (DCs) and a subpopulation of CD11 $\mathrm{b}^{\text {hi }}$ DCs migrate to lung-draining mediastinal lymph nodes (mLNs) during allergic sensitization through the airway. (a, b) Analysis of CD $103^{+}$and CD $11 b^{\text {hi }}$ DCs in the lung (a) and $\mathrm{mLNs}(\mathbf{b})$ under steady-state conditions and $24 \mathrm{~h}$ after instillation of ovalbumin/lipopolysaccharide (OVA/LPS). Shown are representative cytograms of DCs from individual mice, as well as bar histograms showing mean values \pm s.e.m. (c) Cytograms showing migratory $\left(\mathrm{PKH}^{+}\right) \mathrm{DCs}$ in $\mathrm{mLNs}$ under steady-state conditions or after instillation of OVA/LPS. (d) Compiled data of migratory CD $11 \mathrm{~b}^{\mathrm{hi}}$ and $\mathrm{CD} 103^{+} \mathrm{DCs}$ in mLNs. $P$-value by Mann-Whitney test, $n=4$ mice/group. (e) Total DCs. Cytogram showing major DC populations in mLNs of wild-type and $\mathrm{Ccr}^{-1-}$ mice $24 \mathrm{~h}$ after OVA/LPS instillation (left), and histograms showing total number of CD103 ${ }^{+}$and CD $11 b^{\text {hi }}$ DCs under steady-state conditions and after OVA/LPS (right). (f) Migratory DCs. Representative cytogram showing CD103 ${ }^{+}$and CD11 ${ }^{\text {hi }}$ DCs after gating on $\mathrm{PKH}^{+}$migratory DCs and histograms showing numbers of migratory CD103 ${ }^{+}$and CD11 bi ${ }^{\text {hi }} \mathrm{DCs}$ in $\mathrm{mLNs} \mathrm{of} \mathrm{Ccr}^{+/+}$and Ccr7 ${ }^{-/-}$mice. ( $n=4$ mice/group). A representative result of two independent experiments is shown. 
CD $11 b^{\text {hi }}$ DCs, as well as that of $\mathrm{CD}_{103}{ }^{+}$DCs, is critically dependent on CCR7, suggesting that the CD11 $\mathrm{b}^{\text {hi }}$ DCs present in mLNs of $\mathrm{Ccr}^{--}$mice are not emigrants from the lung but likely arise from blood-borne precursors.

\section{$\mathrm{CD}_{103}{ }^{+} \mathrm{DCs}$ and a minor population of $\mathrm{CD} 11 \mathrm{~b}^{\mathrm{hi}} \mathrm{DC}$ in the lung express $\mathrm{Ccr} 7$}

The relatively high migratory activity of $\mathrm{CD}_{103}{ }^{+}$DCs suggested that they might express higher levels of $\mathrm{Ccr} 7$ than do CD $11 b^{\text {hi }}$ DCs. To test this, we purified the two major lung DC subsets and prepared mRNA from them. CD103 ${ }^{+}$DCs expressed more Ccr 7 mRNA than did $C D 11 b^{\text {hi }}$ DCs (Figure 2a). Instillation of LPS increased $\mathrm{Ccr} 7$ expression in both the DC subsets but much more strongly in $\mathrm{CD} 103^{+}$DCs. This higher level of $\mathrm{Ccr} 7 \mathrm{mRNA}$ in $\mathrm{CD}_{103}{ }^{+}$DCs might have been due to a larger proportion of $C c r 7$-expressing cells or to more $C c r 7$ expression on a per cell basis. To distinguish between these possibilities, we attempted to estimate CCR7 display levels on individual cells by flow cytometry. Antibodies to CCR7 bound to this receptor on lung DCs and bone marrow-derived DCs (BMDCs) at $37^{\circ} \mathrm{C}$ but not on ice (see Supplementary Figures S2a,b online). However, incubation of lung leukocytes at $37^{\circ} \mathrm{C}$ altered the display of surface molecules, including MHC class II and CD115 (macrophage colony-stimulating factor receptor), on DCs and monocytes, respectively (see Supplementary Figures S2c,d online). This precluded the simultaneous analysis of CCR7 together with certain other molecules. To circumvent this problem and to study $\mathrm{Ccr} 7$ expression under a variety of conditions without altering cellular phenotypes, we generated $\mathrm{Ccr} 7$ reporter mice in which the green fluorescent protein (GFP) coding region replaces that of $\mathrm{C} r \mathrm{7}$ (see Supplementary Figures S2f-i online). These mice provided a rapid and temperature-independent method to study $\mathrm{C} c r 7$ expression (see Supplementary Figure S2e online). On lung DCs, a much higher proportion of $\mathrm{CD}_{103}{ }^{+}$DCs expressed Ccr7-gfp than did CD11b ${ }^{\text {hi }}$ DCs (Figure 2b), in agreement with the migratory capacities of these two DC subsets.
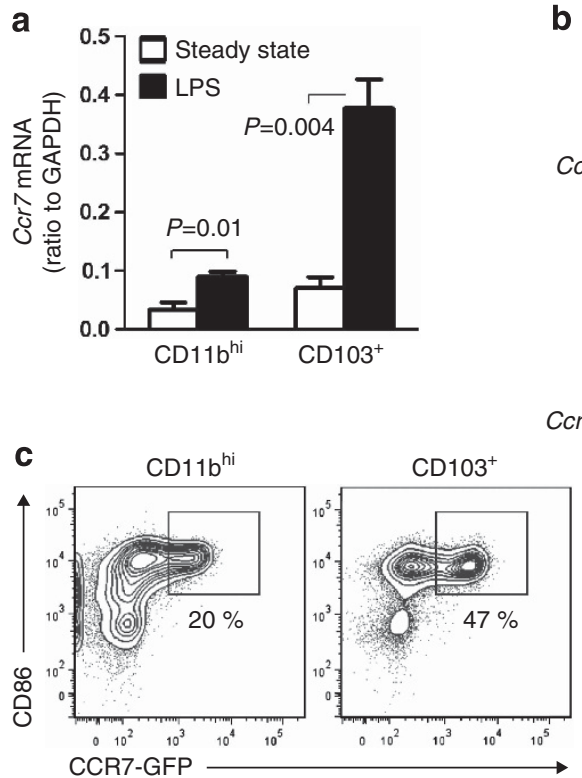

b
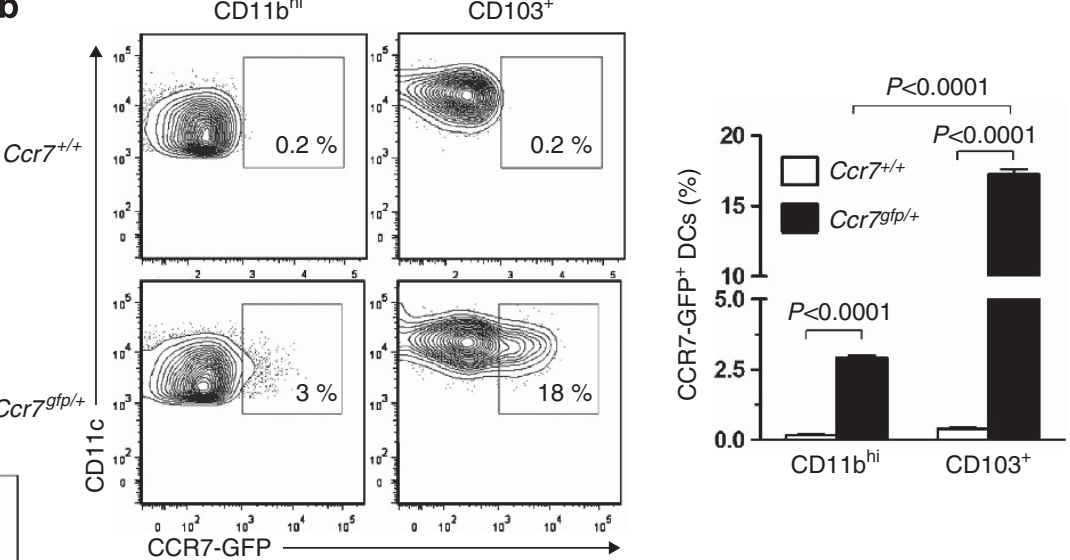

d

Total DCs
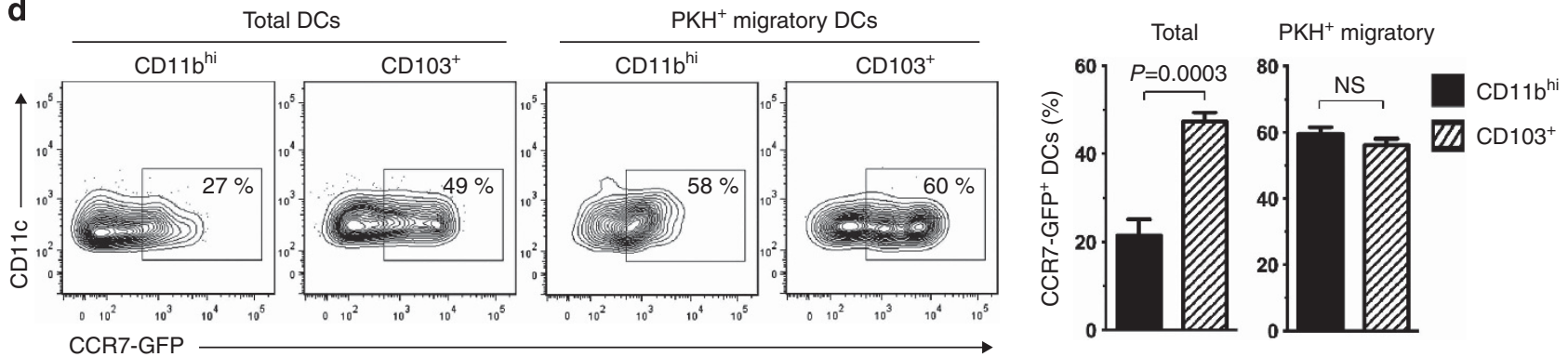

Figure 2 Expression of Ccr7 in pulmonary dendritic cell (DC) subsets. (a) Ccr7 mRNA in CD103 ${ }^{+}$and CD11 ${ }^{\text {hi }}$ lung DCs during steady-state conditions and after lipopolysaccharide (LPS) instillation. (b) CCR7-GFP (CCR7-green fluorescent protein) fluorescence in CD103 ${ }^{+}$and CD11 ${ }^{\text {hi }}$ $\mathrm{DCs}$ from the lungs of Ccr $7^{f p /+}$ mice $24 \mathrm{~h}$ after LPS instillation. Shown are representative cytograms of individual mice, as well as bar histograms showing compiled data of four mice per group. (c) CCR7-GFP fluorescence in purified CD11 $\mathrm{b}^{\text {hi }}$ and CD103 $3^{+}$DCs after $16 \mathrm{~h}$ of ex vivo culture in LPS $\left(0.1 \mu \mathrm{g} \mathrm{ml}^{-1}\right)$-containing media. (d) CCR7-GFP fluorescence in total and PKH ${ }^{+}$migratory DCs of the indicated DC subsets prepared from lymph nodes of $C c r 7^{g f p /+}$ mice. Representative cytograms of individual mice and bar histograms of compiled data for three mice per group are shown. Data shown are from one of two experiments yielding similar results. GAPDH, glyceraldehyde 3-phosphate dehydrogenase; NS, not significant. 
To determine whether the relatively small proportion of $\mathrm{CD} 11 \mathrm{~b}^{\text {hi }}$ DCs expressing $C \mathrm{C} r 7$ is an intrinsic property of these cells or simply due to their being shielded from LPS exposure in vivo, we purified GFP-negative CD11 $\mathrm{b}^{\mathrm{hi}}$ and $\mathrm{CD} 103^{+}$DCs from the lungs of $C c r 7^{g f P}$ mice and stimulated the cells ex vivo with LPS. This treatment increased the proportion of Ccr7-gfpexpressing cells in both DC subsets but did so more effectively in $\mathrm{CD}_{103}{ }^{+}$DCs (Figure 2c). This result indicates that the difference in $\mathrm{Ccr} 7$ expression between the two major lung DC subsets is likely due to intrinsic differences in their potential to express $\mathrm{Ccr} 7$ and not to their anatomical location in the lung.

We next analyzed DCs of mLNs in $C c r 7^{g f P}$ mice. We found that a larger proportion of $\mathrm{CD}_{103}{ }^{+}$DCs expressed Ccr7-gfp than did CD11b ${ }^{\text {hi }}$ DCs (Figure 2d). However, when we restricted our analysis to $\mathrm{PKH}^{+}$DCs that had migrated from the lung, the frequency of CCR7-GFP ${ }^{+}$DCs was comparable between the $\mathrm{CD} 11 \mathrm{~b}^{\text {hi }}$ and $\mathrm{CD} 103^{+}$subsets. This finding is in agreement with the requirement of CCR7 for migration of $\mathrm{CD}_{103}{ }^{+}$and $\mathrm{CD} 11 \mathrm{~b}^{\mathrm{hi}}$ DCs to draining LNs (Figure 1f).

\section{CD14 ${ }^{\text {hi }}$ and Ly-6C ${ }^{\text {hi }}$ CD11b ${ }^{\text {hi }}$ DCs do not express Ccr7 or migrate to $\mathrm{mLNs}$}

To better characterize the migratory properties of CD1 $1 b^{\text {hi }}$ DCs, we studied subpopulations of DCs in this subset. We first investigated inflammatory DCs, a subset of CD $11 b^{\text {hi }}$ DCs that are derived from monocytes and are rapidly recruited to the airways by pro-inflammatory stimuli. ${ }^{15}$ As remnants of their monocytic heritage, inflammatory moDCs express high levels of Ly-6C..$^{15,37,38}$ To determine whether these cells are migratory, we instilled LPS or polyinosinic-polycytidylic acid (poly (I:C)) into the airways of $C c r 7^{g f P}$ mice. As expected, many $\mathrm{CD} 103^{+}$DCs and a population of CD $11 \mathrm{~b}^{\text {hi }}$ DCs that expressed high levels of MHC class II also expressed Ccr7-gfp (Figure 3a). However, Ly- $6 C^{\text {hi }} C D 11 b^{\text {hi }}$ inflammatory DCs expressed very low levels of Ccr7-gfp compared with Ly- $6 C^{\text {lo }} C D 11 b^{\text {hi }}$ DCs (Figure 3b). These data indicate that the Ly-6 $\mathrm{C}^{\text {hi }}$ inflammatory DCs that are rapidly recruited to the lung by pro-inflammatory stimuli do not express high levels of Ccr7.

In addition to inflammatory DCs, monocytes are reported to give rise to CD11 ${ }^{\text {hi }}$ DCs that express high levels of the LPS coreceptor, $\mathrm{CD} 14$, even during steady-state conditions. ${ }^{16,29,30} \mathrm{We}$ found that Ccr7-gfp was expressed in CD11 $\mathrm{b}^{\mathrm{hi}} \mathrm{DCs}$ displaying intermediate or low levels of CD14 $\left(\mathrm{CD} 14^{\mathrm{med} / \mathrm{lo}}\right) \mathrm{DCs}$ but not in CD14 ${ }^{\text {hi }}$ DCs (Figure 3c). Thus, neither Ly-6C ${ }^{\text {hi }}$ inflammatory DCs nor CD $14{ }^{\text {hi }} \mathrm{CD} 11 \mathrm{~b}{ }^{\mathrm{hi}}$ DCs express high levels of $\mathrm{Ccr}$.

The low expression of $\mathrm{Ccr} 7$ seen in $\mathrm{CD} 14^{\mathrm{hi}} \mathrm{CD} 11 \mathrm{~b}^{\mathrm{hi}} \mathrm{DCs}$ might have been due to a constraint imposed on them during their differentiation from monocytes. Alternatively, the anatomical location of these cells within the lung might have shielded them from signals that promote $\mathrm{Ccr} 7$ expression. To distinguish between these possibilities, we purified CCR7-GFPnegative DCs from the lungs of untreated $C c r 7^{g f p}$ mice and fractionated the cells into three subsets: $\mathrm{CD} 103^{+} \mathrm{DCs}$, $\mathrm{CD} 14^{\mathrm{med} / \mathrm{lo}} \mathrm{CD} 11 \mathrm{~b}{ }^{\text {hi }}$ DCs, and CD $14^{\mathrm{hi}} \mathrm{CD} 11 \mathrm{~b}{ }^{\text {hi }}$ DCs. The cells were cultured in the presence of LPS to promote their maturation and induce Ccr7. Increased display of CD86 confirmed maturation of almost all DCs in these cultures. Most $\mathrm{CD} 103^{+}$DCs, as well as most $\mathrm{CD} 14^{\mathrm{med} / \mathrm{lo}} \mathrm{CD} 11 \mathrm{~b}^{\mathrm{hi}}$ cDCs, displayed marked increase in CCR7-GFP. By contrast, very little increase in CCR7-GFP was seen for CD $14^{\text {hi }} C D 11 b^{\text {hi }}$ DCs (Figures 3d,e). This result suggests that $\mathrm{CD} 14^{\mathrm{hi}} \mathrm{CD} 11 \mathrm{~b}^{\mathrm{hi}}$ DCs in the lung do not express $\mathrm{Ccr} 7$, even after their activation with LPS.

\section{Absence of Ly-6C ${ }^{\text {hi }}$ CD11 $b^{\text {hi }}$ DCs does not diminish lung DC migration}

Ly-6C and CD14 are displayed on moDCs, ${ }^{15,16,37,38}$ but it is unclear whether these markers define distinct populations of moDCs. To address this question, we instilled LPS into the airways of mice to induce pulmonary inflammation and followed the surface marker profile of CD11 bi $\mathrm{DCs}$ over time. In the lungs of untreated mice, very few Ly- $6 C^{\text {hi }}$ inflammatory DCs were seen, and CD11bi DCs were comprised of CD14 $4^{\mathrm{hi}}$ and $\mathrm{CD} 14^{\mathrm{med} / \mathrm{lo}}$ cells (Figures $4 \mathbf{a}, \mathbf{b}$ ). The CD14b ${ }^{\text {hi }}$ DCs likely represented moDCs, which were previously reported to reside in the lung even during steadystate conditions. ${ }^{29,30}$ Within one day of OVA/LPS instillation, we observed a rapid rise in total DCs, with most of these being Ly- $6 \mathrm{C}^{\text {hi }}$ inflammatory DCs that were readily distinguished from the other two populations of $\mathrm{CD} 11 \mathrm{~b}^{\text {hi }} \mathrm{DCs}$. By day 3 postOVA/LPS instillation, the number of Ly- $6 \mathrm{C}^{\text {hi }}$ inflammatory DCs in the lung had declined rapidly, and a corresponding increase was seen in CD14b ${ }^{\text {hi }} \mathrm{Ly}-6 \mathrm{C}^{\mathrm{lo}}$ and CD $14^{\mathrm{med} / \mathrm{lo}} \mathrm{Ly}-6 \mathrm{C}^{\mathrm{lo}}$ DCs. This trend continued over the next several days. Thus, inflammatory DCs are relatively short-lived, compared with the other CD11b ${ }^{\text {hi }}$ DC subsets.

Rapid and robust accumulation of Ly- $6 \mathrm{C}^{\text {hi }}$ inflammatory DCs to the inflamed lung is mediated largely by the chemokine receptor, CCR2. ${ }^{15,37,39}$ Analysis of Ccr2-deficient mice (see Supplementary Figures S3a-e online) revealed that during steady-state conditions, these mice have as many or more $\mathrm{CD} 11 \mathrm{~b}^{\text {hi }}$ and $\mathrm{CD} 103^{+}$pulmonary DCs as wild-type mice (Figure 4c). However, after instillation of OVA/LPS, $\mathrm{Ccr}^{-/-}$mice have reduced $\mathrm{CD} 11 \mathrm{~b}^{\text {hi }}$ DCs. This reduction is due largely to a paucity of Ly- $6 \mathrm{C}^{\text {hi }}$ inflammatory DCs, which are recruited in large numbers to the lungs of wild-type mice following OVA/LPS installation (Figure 4d). The other DC subsets, $\mathrm{CD} 103^{+}$DCs, CD $14^{\text {hi }}$ Ly-6C ${ }^{\text {lo }}$ DCs, and CD $14^{\mathrm{med} /}$ ${ }^{10} \mathrm{Ly}-6 \mathrm{C}^{\mathrm{lo}} \mathrm{DCs}$, were comparable between $\mathrm{C} \mathrm{cr} 2^{-/-}$mice and wild-type mice or even slightly increased in the former strain (Figure 4d). We next studied how the absence of inflammatory moDCs in $\mathrm{Ccr}^{-/-}$mice affected overall levels of $\mathrm{Ccr} 7$ expression in DCs. Wild-type and $\mathrm{Ccr}^{-/-}$mice were treated with LPS, and $\mathrm{CD} 11 \mathrm{~b}{ }^{\text {hi }}$ and $\mathrm{CD}_{103}{ }^{+}$DCs were purified by cell sorting. No differences in $\mathrm{C} c r 7$ expression were seen for $\mathrm{CD}_{103}{ }^{+}$DCs, an expected result because these DCs are present at similar numbers in these two mouse strains. However, CD11b ${ }^{\text {hi }}$ DCs from $\mathrm{Ccr}^{-/-}$mice had much higher levels of $\mathrm{Ccr} 7$ than their counterparts in wild-type mice. This result is consistent with the low levels of $\mathrm{Ccr} 7$ expression in 
a
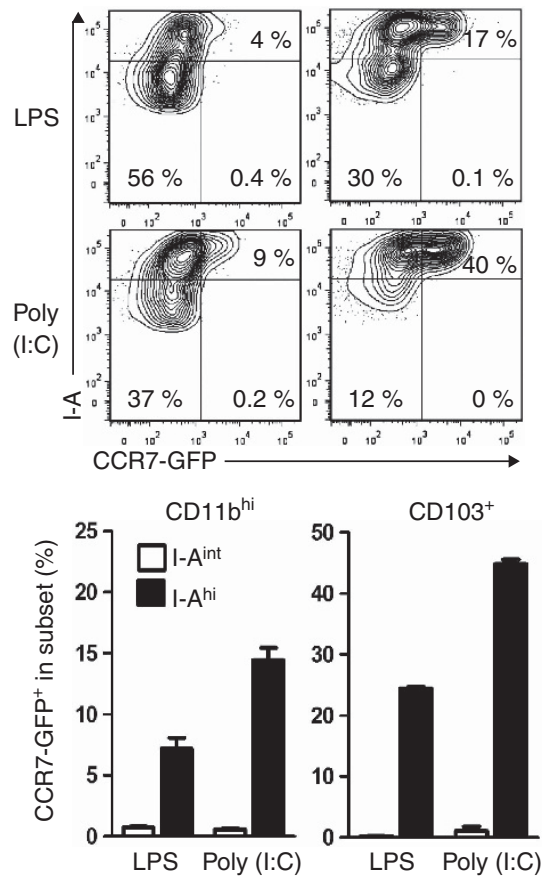

b

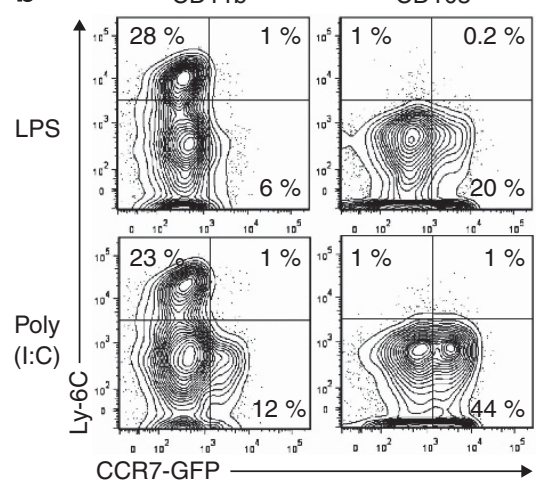

CD11 $b^{h}$

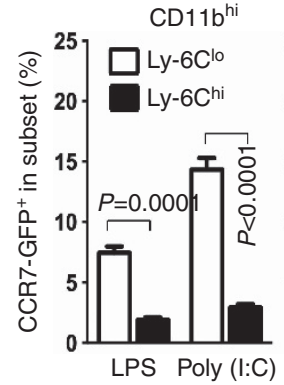

$\mathrm{CD}_{103^{+}}$

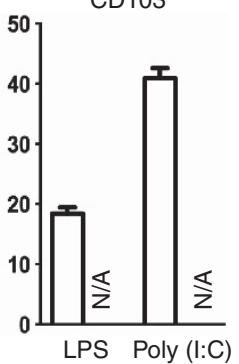

C

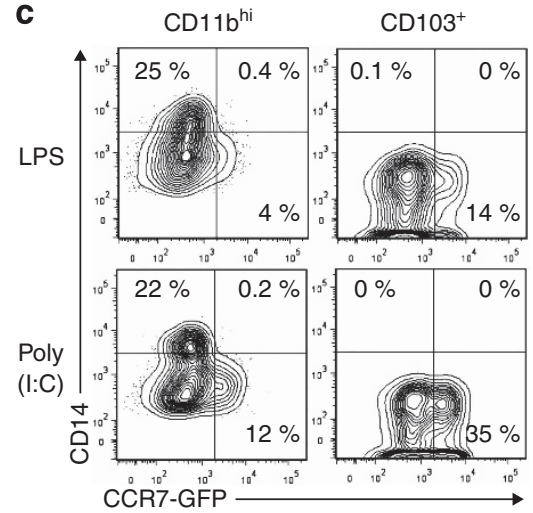

CD11b ${ }^{\text {hi }}$

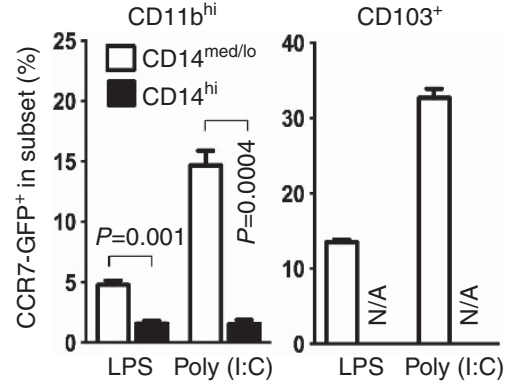

d

Pre culture

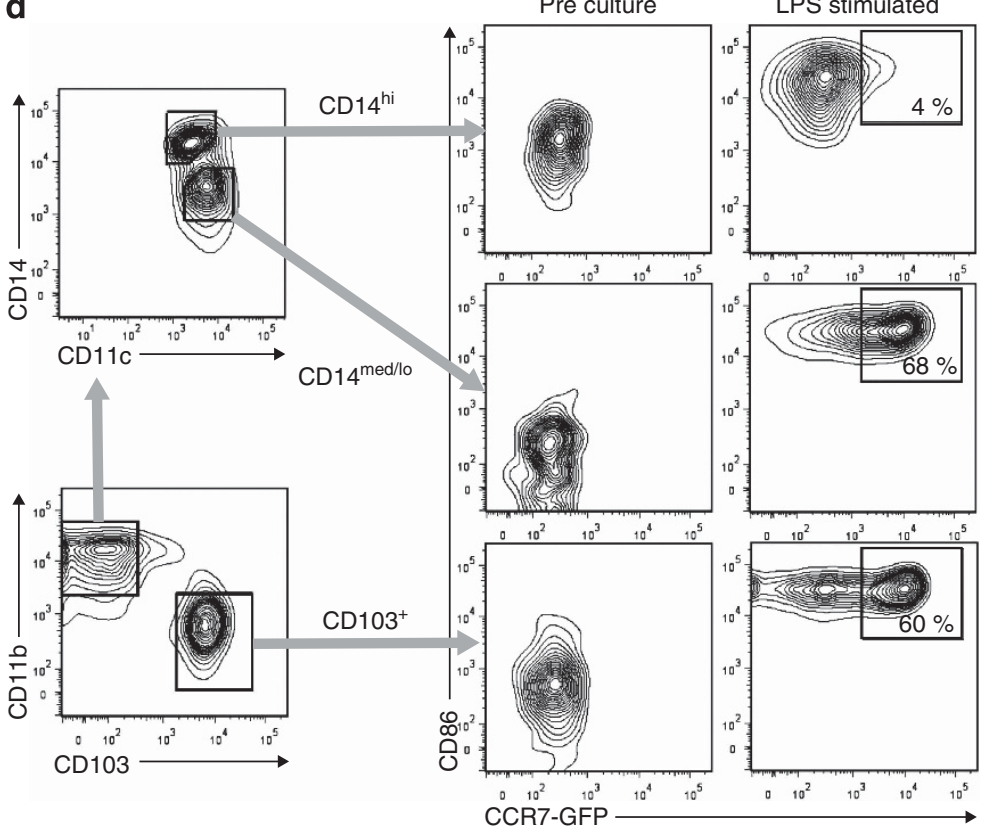

e

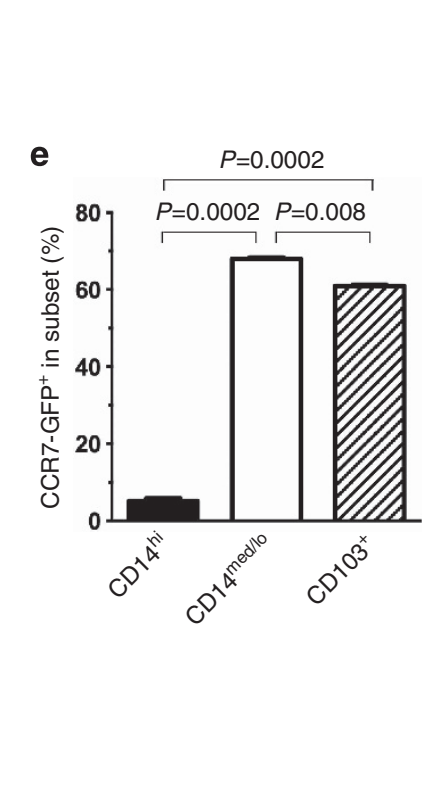

Figure 3 Ccr7 expression in CD11 $b^{\text {hi }}$ dendritic cells (DCs) is restricted to Ly-6C ${ }^{\text {lo } C D 14}{ }^{\text {med/lo }}$ DCs. (a-c) Co-production of CCR7-GFP (CCR7-green fluorescent protein) with I-A (a), Ly-6C (b), or CD14 (c) in the indicated pulmonary DC subsets $24 \mathrm{~h}$ after instillation of lipopolysaccharide (LPS) or polyinosinic-polycytidylic acid (poly (I:C)). ( $n=3$ mice/group). A representative result of two independent experiments is shown. (d) Gating strategy for purifying CD1 $4^{\text {hi }} C D 11 b^{\text {hi }}, C D 14^{\text {med/lo }} \mathrm{CD} 11 \mathrm{~b}^{\text {hi }}$, and CD $103^{+}$DCs from the lung (left) and expression of CCR7-GFP before and after ex vivo culture of the cells in LPS-containing media (right). Levels of CD86 are also shown. (e) Compiled data ( $n=2 / g r o u p)$ of CCR7-GFP expression in the indicated DC subsets following LPS stimulation ex vivo. N/A, not applicable.

inflammatory DCs (Figure 3b) and suggests that large number of inflammatory DCs in LPS-treated wild-type mice dilutes overall expression of this gene in CD11b ${ }^{\text {hi }}$ DCs, whereas this effect is not seen in $\mathrm{Ccr}^{-/-}$mice because they lack inflammatory DCs (Figure 4e). In agreement with this interpretation, we found that the number of migratory, $\mathrm{PKH}^{+} \mathrm{CD}_{11 \mathrm{~b}}{ }^{\mathrm{hi}}$ DCs was higher in mLNs of $\mathrm{Ccr} 2^{-/-}$mice than in wild-type mice (Figure 4f). Taken together, these observations provide additional evidence that Ly-6Chi inflammatory DCs are non-migratory. 
a

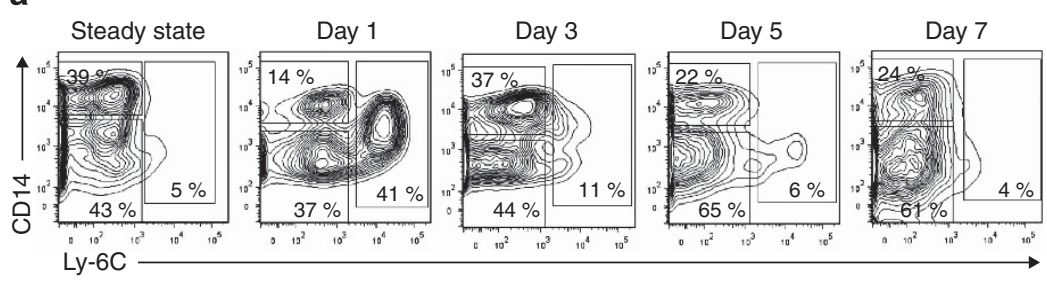

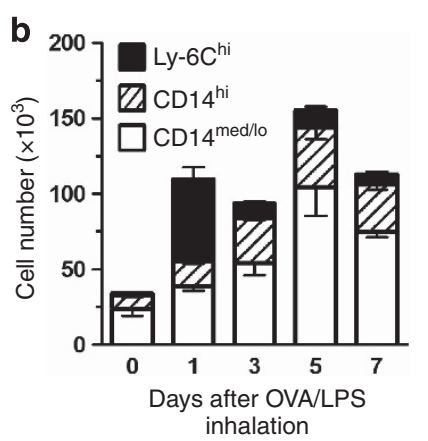

C
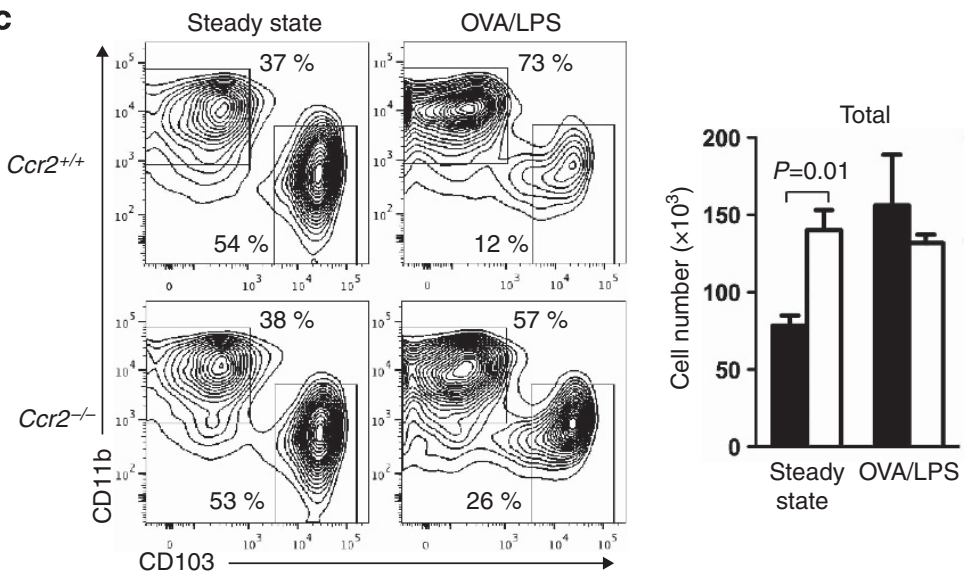
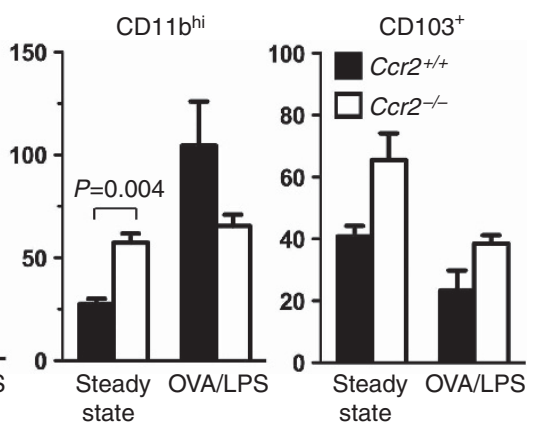

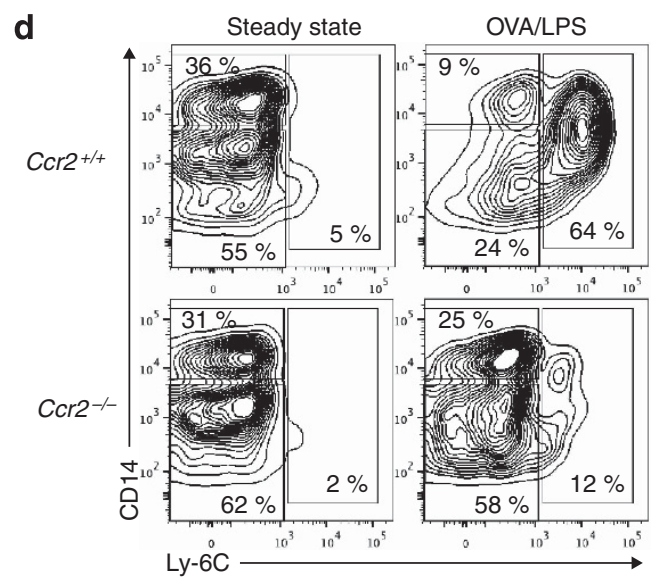

Ly-6C $\mathrm{C}^{\text {hi }}$

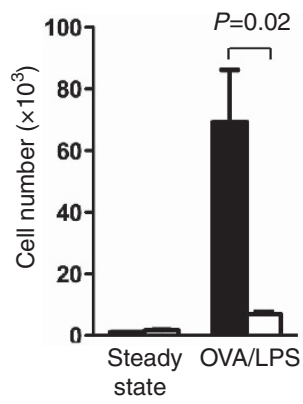

CD14hi

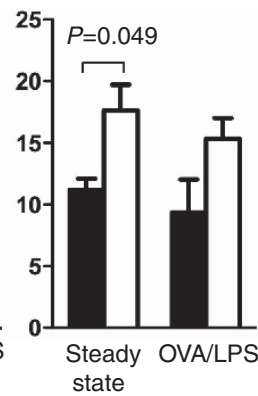

CD14 $4^{\mathrm{med} / \mathrm{lo}}$
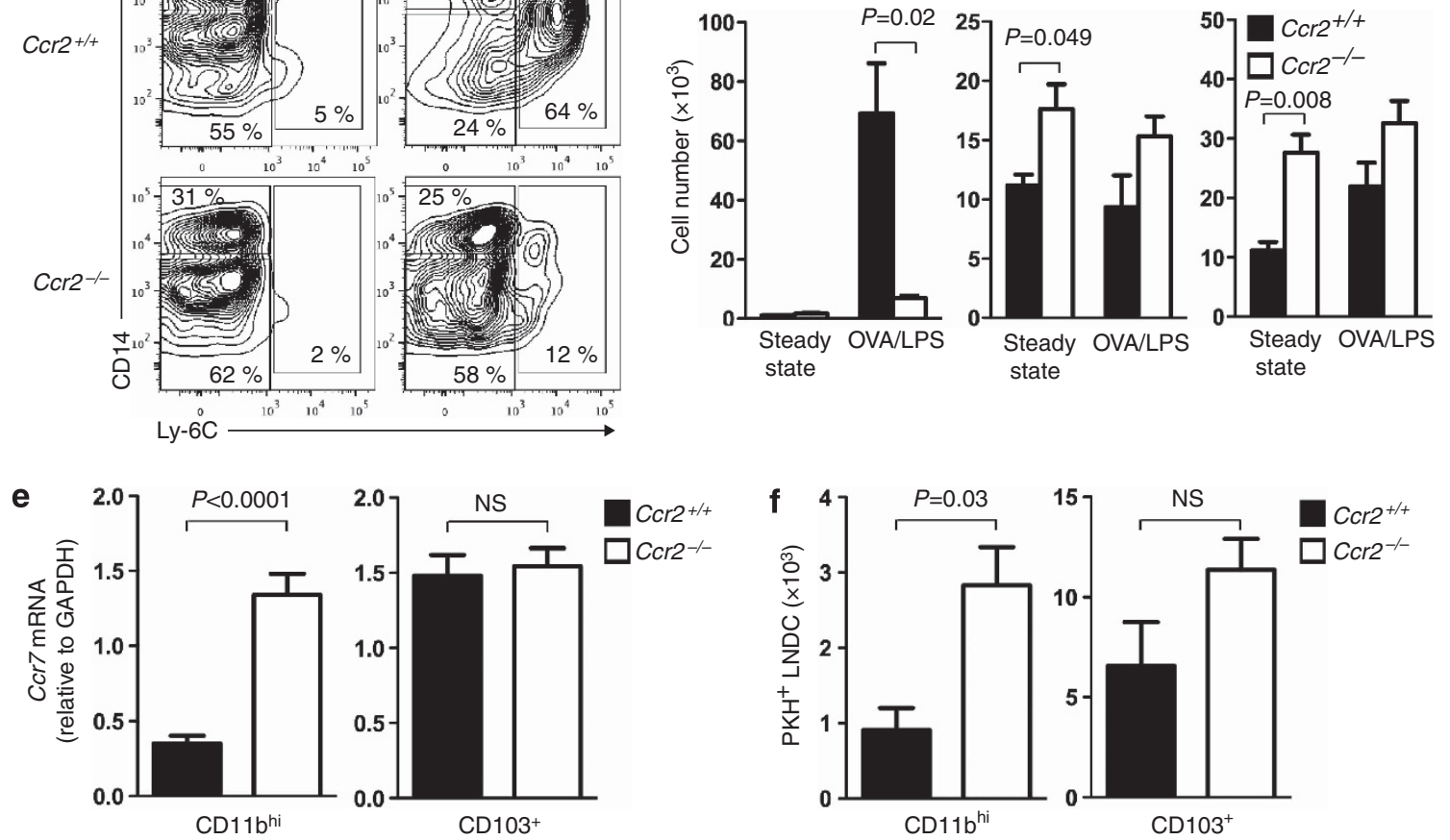

Figure 4 Analysis of three distinct subpopulations of CD11 $\mathrm{b}^{\text {hi }}$ dendritic cells (DCs) in the lung. (a) Cytograms showing CD14 and Ly-6C staining of DCs within a CD11 $\mathrm{b}^{\text {hi }} \mathrm{CD} 11 \mathrm{c}^{+} \mathrm{I}-\mathrm{A}^{+}$gate at the indicated times following ovalbumin/lipopolysaccharide (OVA/LPS) instillation and (b) absolute number of cells in each subpopulation. (c) Cytograms showing CD103 and CD11b staining of total lung DCs in wild-type and Ccr2 ${ }^{-/}-$mice $^{-}$ (left). Also shown are numbers of total, CD11 $\mathrm{b}^{\text {hi }}$, and $\mathrm{CD} 103^{+}$lung DCs under steady-state conditions and 16 h after OVA/LPS instillation (right) $(n=3)$. (d) Cytograms showing CD14 and Ly-6C staining of CD11b $\mathrm{b}^{\text {hi }}$ lung DCs in wild-type and Ccr2 ${ }^{-\prime-}$ mice (left). Numbers of Ly-6C ${ }^{\text {hi }}$ CD14 ${ }^{\text {hi }}$, and CD14 ${ }^{\mathrm{med} / \mathrm{lo}}$ DCs under steady-state conditions and $16 \mathrm{~h}$ after OVA/LPS instillation are shown (right) $(n=3)$. (e) Ccr7 mRNA levels in the indicated lung DC subsets of LPS-treated mice $(n=2$ to 7$)$. (f) Number of $\mathrm{PKH}^{+}$migratory CD11b ${ }^{\text {hi }}$ and CD103 ${ }^{+} \mathrm{DCs}_{\text {in }}$ the mediastinal lymph nodes (LNs) of wild-type and $C c r 2^{-1-}$ mice $24 \mathrm{~h}$ after LPS instillation $(n=3)$. A representative result of two independent experiments is shown. GAPDH, glyceraldehyde 3-phosphate dehydrogenase; NS, not significant. 


\section{CD14 ${ }^{\text {hi }}$ and Ly-6C ${ }^{\text {hi }}$ CD11b ${ }^{\text {hi }}$ DCs in the lung are non-migratory}

Our experiments thus far suggested that CD11 $b^{\text {hi }}$ DCs in the lung are comprised of migratory CD14 ${ }^{\mathrm{med} / \mathrm{lo}}$ DCs and non-

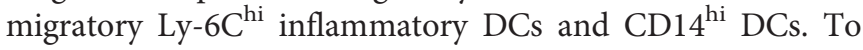
confirm this, LPS instillation was used to recruit inflammatory DCs to the lung, and these cells, as well as the other DCs in the lung, were labeled by instillation of PKH (Figure 5a). On the following day, the lungs and mLNs were excised and analyzed for the presence of PKH-labeled DCs. In the lung, the majority of $\mathrm{PKH}^{+} \mathrm{CD} 11 \mathrm{~b}^{\text {hi }}$ DCs were Ly-6Chi inflammatory DCs (Figure 5b, top). However, in mLNs, almost all $\mathrm{PKH}^{+}$
CD $11 b^{\text {hi }}$ DCs were CD14 ${ }^{\text {med/lo }}$ Ly-6C ${ }^{\text {lo }}$ DCs (Figure 5b, middle). To circumvent possible differences in the ability of various pulmonary $\mathrm{DC}$ subsets to be labeled with $\mathrm{PKH}$, we calculated a migration index based on the ratio of $\mathrm{PKH}^{+} \mathrm{CD} 11 \mathrm{~b}^{\text {hi }}$ DCs in $\mathrm{mLNs}$ to $\mathrm{PKH}^{+} \mathrm{CD} 11 \mathrm{~b}^{\text {hi }}$ DCs in the lung (Figure 5b, bottom). This calculation confirmed that $\mathrm{CD} 14^{\mathrm{med} / \mathrm{l}} \mathrm{Ly}-6 \mathrm{C}^{\mathrm{lo}}$ pulmonary DCs are migratory, whereas $\mathrm{CD} 14^{\text {hi }} \mathrm{DCs}$ and Ly- $6 \mathrm{C}^{\text {hi }}$ DCs are much less migratory. Thus, inflammatory DCs are rapidly recruited to the lung following LPS inhalation, but they do not migrate to draining LNs. In agreement with this observation, CCR7-GFP was seen in the Ly-6 $\mathrm{C}^{\mathrm{lo}}$ population of CD11b ${ }^{\text {hi }}$ DCs in mLNs but not in the Ly- $6 \mathrm{C}^{\text {hi }}$ population in mLNs (Figure $5 \mathbf{c}$ ). a
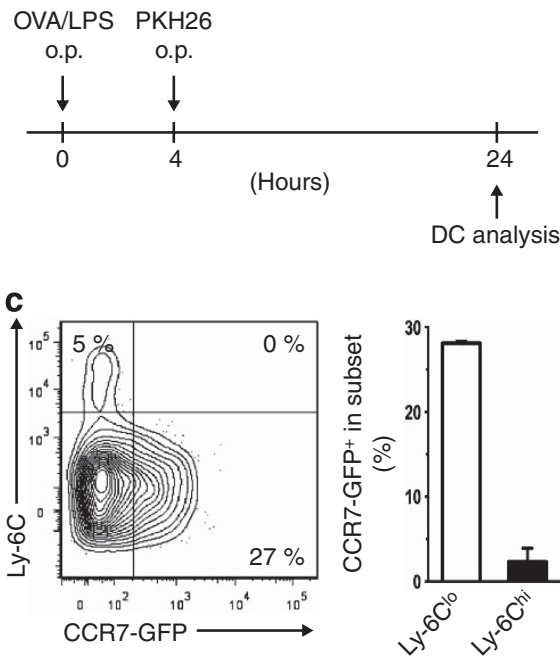

d

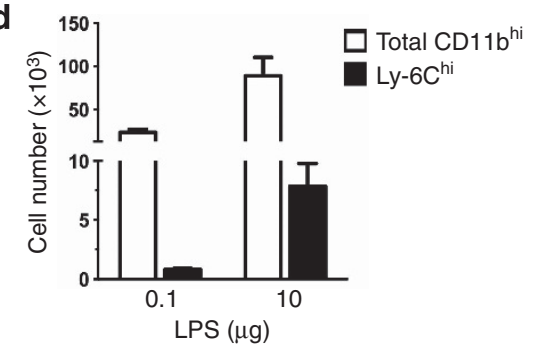

e

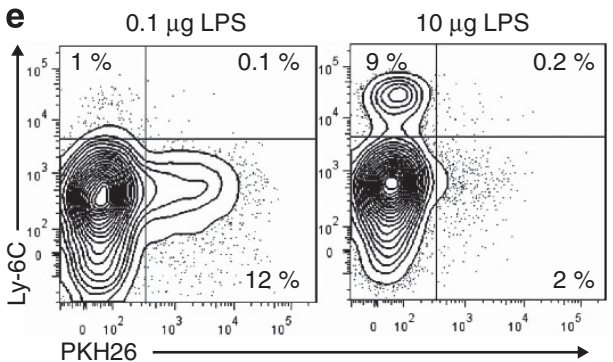

b
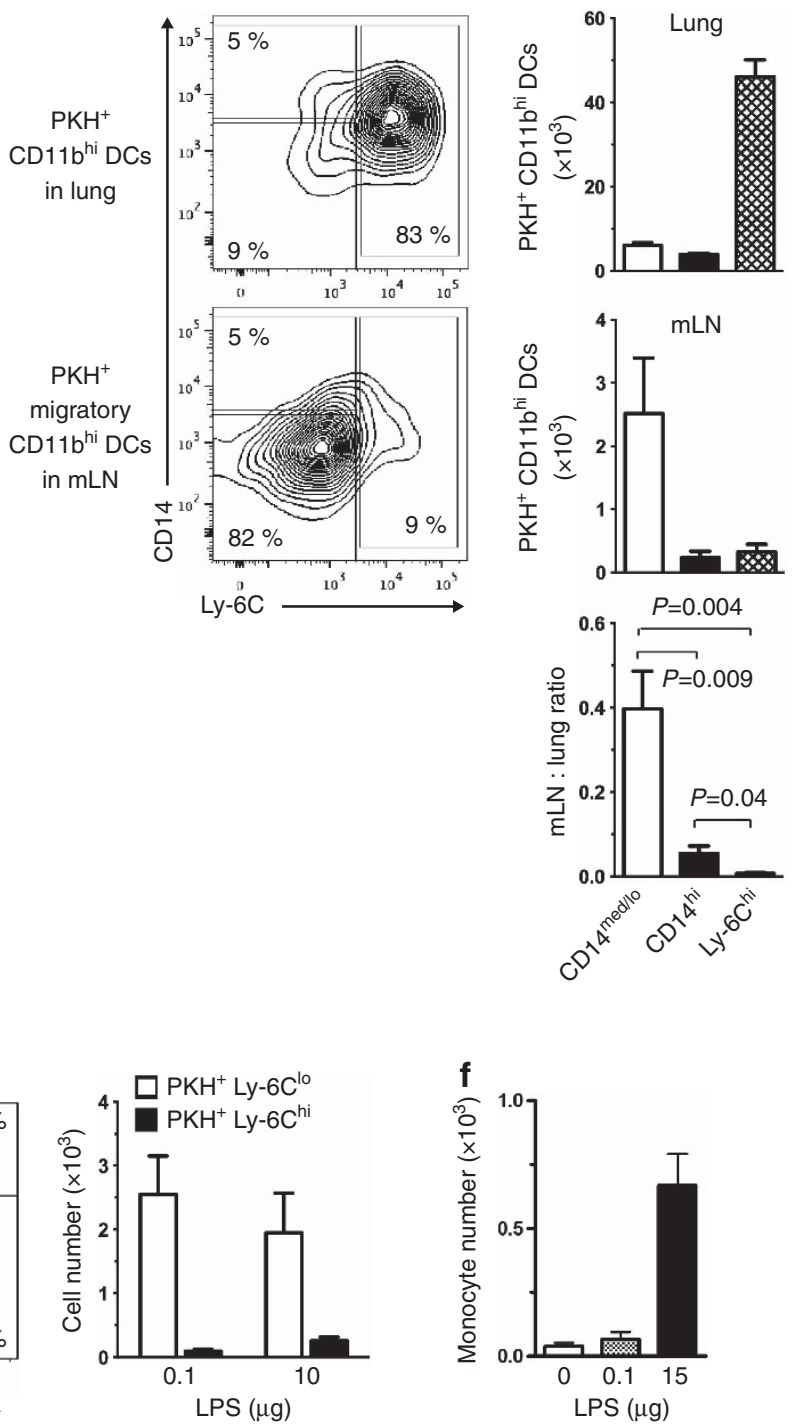

Figure 5 Inflammatory dendritic cells (DCs) in the lung do not migrate to mediastinal lymph nodes (mLNs). (a) Timeline for instillation of lipopolysaccharide (LPS) and PKH. (b) Ly-6C and CD14 display on $\mathrm{PKH}^{+}$CD11b ${ }^{\text {hi }}$ DCs from the lung (top) and mLNs (middle). Representative cytograms for individual mice are shown, as well as compiled results for five mice. Also shown is the ratio of the PKH ${ }^{+}$cells in $\mathrm{mLNs}$ and the lung (bottom). (c) Expression of Ccr7-gfp and staining for Ly-6C on CD11 b $\mathrm{b}^{\mathrm{hi}} \mathrm{mLN}$ DCs of Ccr $7^{f f p /+}$ mice $(n=2)$. (d) Total and Ly-6C ${ }^{\text {hi }}$ CD $11 \mathrm{~b}^{\mathrm{hi}}$ inflammatory DCs in $\mathrm{mLNs}$ following instillation of either low- $(0.1 \mu \mathrm{g})$ or high $(10 \mu \mathrm{g})$-dose LPS. (e) Ly-6C and PKH staining of CD11 $\mathrm{b}^{\text {hi }}$ DCs in $\mathrm{mLNs}$ after LPS instillation. Representative cytograms and compiled results $(n=3)$ are shown. (f) Accumulation of inflammatory monocytes in $\mathrm{mLNs} 2 \mathrm{~h}$ after intravenous injection of $10^{6}$ CFSE (carboxyfluorescein diacetate succinimidyl ester)-labeled Ly-6Chi CD11 bi bone marrow cells into recipient mice. Animals were instilled with the indicated amount of LPS $24 \mathrm{~h}$ before monocyte transfer $(n=2)$. o.p., oropharyngeal; OVA, ovalbumin. 
Previous reports have shown that substantial numbers of Ly-6C ${ }^{\text {hi }}$ inflammatory DCs are present in mLNs in the setting of acute inflammation, ${ }^{37}$ although it has been unclear whether these cells emigrated from the lung. To test the possibility that a stronger pro-inflammatory stimulus is required to promote Ly-6Chi inflammatory DC migration to mLNs, we instilled 0.1 or $10 \mu \mathrm{g}$ of LPS into the airways of mice. The recruited inflammatory DCs were subsequently labeled with PKH and their migration to mLNs assessed on the following day. The high-dose LPS led to a robust increase in total Ly- $6 \mathrm{C}^{\text {hi }} \mathrm{CD} 11 \mathrm{~b}^{\mathrm{hi}}$ DCs in mLNs compared with treatment with the low-dose LPS (Figure 5d). However, very few of these DCs were stained with $\mathrm{PKH}$; almost all of the $\mathrm{PKH}^{+} \mathrm{CD}_{11 \mathrm{~b}}{ }^{\text {hi }}$ DCs in the LN were Ly-6C ${ }^{\text {lo }}$ (Figure 5e). These results suggest that inflammatory DCs do not migrate from the lung to mLNs, even in the setting of acute inflammation.

The increase in non-migratory, Ly-6C ${ }^{\text {hi }}$ DCs in mLNs of LPS-treated mice prompted us to investigate the origin of these cells. Ly- $6 \mathrm{C}^{\text {hi }}$ monocytes were prepared from BM, labeled with CFSE, and transferred into mice that had received instillations of either low- or high-dose LPS. In mice given low-dose LPS, relatively few CFSE-labeled Ly- $6 \mathrm{C}^{\text {hi }}$ monocytes were seen in mLNs. However, in mice given high-dose LPS, these cells were markedly increased (Figure 5f). Together, these data suggest that the Ly-6C $\mathrm{C}^{\text {hi }}$ inflammatory DCs that accumulate in mLNs during acute inflammation are not migratory DCs arriving from the lung but are descendants of monocytes recruited directly from the blood to mLNs.

Our findings with moDCs in the lung were in apparent contrast to a previous report indicating CCR7-dependent accumulation of moDCs in skin-draining LNs. ${ }^{16}$ In agreement with that study, we found that after systemic LPS injection into $C c r 7^{g f P}$ mice, skin-draining LNs contained many $C c r 7^{8 f P_{-}}$ expressing CD $11 b^{\text {hi }}$ DCs, CD $14^{\text {hi }}$ DCs, and CD $103^{+}$DCs but no $C c r 7^{8 f p}$-expressing Ly-6C ${ }^{\text {hi }}$ inflammatory DCs (see Supplementary Figures S4a,b online). We also confirmed that some in vitro generated moDCs also have the capacity to express Ccr7 (see Supplementary Figures S4c-e online). Together, these data suggest that inflammatory DCs do not express $\mathrm{Ccr} 7$, but its expression in $\mathrm{CD} 14^{\mathrm{hi}}$ DCs is tissuedependent.

\section{Ly-6C ${ }^{\text {hi }}$ and CD14 $4^{\text {hi }}$ DCs are monocyte-derived and develop independently of FLT3L}

We next investigated whether the diverse migratory potential of the various $C D 11 b^{\text {hi }} \mathrm{DC}$ subpopulations in the lung was related to their developmental pathways. We reasoned that Flt $3 \mathrm{~L}^{-/-}$ mice would be useful in this regard because these mice lack CDPs, ${ }^{25,26,40}$ which can differentiate into $\mathrm{CDCs}^{25,26}$ but not monocytes. Flt $3 L^{-/-}$mice also lack $\mathrm{CD} 103^{+} \mathrm{DCs}^{27}$ a finding that we confirmed for untreated and OVA/LPS-treated mice (Figure 6a). However, we noticed that the lungs of $\mathrm{Flt} 3 \mathrm{~L}^{-/-}$mice do contain CD11b ${ }^{\text {hi }}$ DCs, albeit at a slightly reduced number compared with wild-type mice. More detailed analysis revealed that during steady-state conditions, pulmonary CD11b $\mathrm{b}^{\text {hi }}$ DCs in Flt $3 \mathrm{~L}^{-/-}$mice are comprised almost exclusively of the CD $14^{\mathrm{hi}}$ subset, with very few CD14 ${ }^{\mathrm{med} / \mathrm{lo}}$ DCs (Figure 6b). Upon stimulation with OVA/LPS, Ly-6C ${ }^{\text {hi }}$ DCs accumulated in the lungs of $\mathrm{Flt}_{3 L^{-/}}$mice to a similar extent as in wild-type mice, whereas the number of CD14 ${ }^{\text {med/lo }}$ DCs remained low. These data suggest that the $\mathrm{CD} 14^{\mathrm{med} / \mathrm{lo}} \mathrm{CD} 11 \mathrm{~b}^{\mathrm{hi}}$ DCs lacking in Flt3L $L^{-/}$mice are likely CDP-derived, whereas Ly-6 $6 \mathrm{Ch}^{\text {hi }} \mathrm{DCs}$ and $\mathrm{CD} 14^{\text {hi }} \mathrm{CD} 11 \mathrm{~b}^{\text {hi }}$ DCs are monocyte-derived.

To confirm that monocytes give rise to Ly- $6 \mathrm{C}^{\text {hi }}$ inflammatory DCs and CD $14^{\text {hi }}$ DCs, we prepared Ly- $6 \mathrm{C}^{\text {hi }}$ inflammatory monocytes $\left(\mathrm{CD} 11 \mathrm{~b}^{+} \mathrm{Ly}-6 \mathrm{C}^{\mathrm{hi}} \mathrm{CD} 115^{+} \mathrm{CD} 11 \mathrm{c}^{-} \mathrm{I}_{-\mathrm{A}^{-}}\right)$ (see Supplementary Figures S5a, b and Supplementary Methods online) from the BM of CD45.1 mice and adoptively transferred these cells to CD45.2-recipient mice, whose airways had been instilled with OVA/LPS before the monocyte transfer. By gating on $\mathrm{CD} 45.1^{+} \mathrm{I}-\mathrm{A}^{+} \mathrm{CD} 11 \mathrm{c}^{+}$cells, we were able to follow the fate of moDCs in the lung (Figure 6c). At one day post-transfer, almost all of these cells were Ly- $6 \mathrm{C}^{\text {hi }}$ inflammatory DCs. Over time, the total number of donor moDCs in the lung declined, and CD14 ${ }^{\text {hi }}$ DCs became dominant population (Figures $\mathbf{6 c}$,d). Importantly, very few Ly- $6 \mathrm{C}^{\mathrm{lo}} \mathrm{CD} 14^{\mathrm{med} / \mathrm{lo}} \mathrm{DCs}$ were seen within the CD $45.1^{+}$gate, suggesting that monocytes give rise to $\mathrm{Ly}-6 \mathrm{C}^{\mathrm{hi}}$ inflammatory DCs and $\mathrm{CD} 14^{\mathrm{hi}} \mathrm{CD} 11 \mathrm{~b}^{+}$DCs but not to Ly${ }_{6} \mathrm{C}^{\mathrm{lo}} \mathrm{CD} 14^{\mathrm{med} / \mathrm{lo}} \mathrm{CD} 11 \mathrm{~b}{ }^{+}$DCs.

\section{Migratory DCs in the lung are FLT3/FLT3L-dependent cDCs} Our experiments with PKH staining of pulmonary DCs had shown that $\mathrm{CD} 14^{\text {hi }}$ moDCs were significantly less migratory than $\mathrm{CD} 14^{\mathrm{med} / \mathrm{lo}} \mathrm{cDCs}$. Nonetheless, we did detect some PKH ${ }^{+}$ CD14 ${ }^{\text {hi }}$ DCs in mLNs (Figure 5b). Although display levels of CD14 are useful to distinguish CD $14^{\text {hi }}$ moDCs from CD $14^{\mathrm{med} /}$ lo $\mathrm{cDCs}$, these populations were not widely separated in our cytograms, leaving open the possibility that there is some overlap in CD14 expression between CDP-derived and monocyte-derived CD11b $b^{\text {hi }}$ DCs. To independently study the migration of these two DC subsets, we carried out a series of experiments with Flt3L-deficient mice, which had a dramatic reduction in $\mathrm{CD} 144^{\mathrm{med} / \mathrm{lo}} \mathrm{CD} 11 \mathrm{~b}{ }^{\text {hi }}$ DCs but normal levels of $\mathrm{CD} 14^{\mathrm{hi}} \mathrm{CD} 11 \mathrm{~b}{ }^{\mathrm{hi}} \mathrm{DCs}$ (Figure $\mathbf{6 b}$ ). The latter appeared to be mature, as judged by their high levels of CD86 and I-A (see Supplementary Figure S5c online) and by the presence of dendrites (see Supplementary Figure S5d online). Furthermore, total lung DCs from $\mathrm{Flt}_{3} \mathrm{~L}^{-/-}$mice efficiently stimulated naive $\mathrm{CD}^{+}{ }^{+} \mathrm{T}$-cell differentiation to Th1 cells, as measured by production of IFN- $\gamma$ (see Supplementary Figure S5e online). The latter finding is in agreement with previous reports showing preferential Th1 induction by moDCs. ${ }^{16,37,38}$ Th2 induction by total DCs prepared from $\mathrm{Flt}_{3 \mathrm{~L}^{-/-}}$mice was impaired, likely because they lack $\mathrm{CD}_{103^{+}}$DCs, which efficiently prime Th2 differentiation. ${ }^{13}$ Thus, based on their expression of MHC class II, DC-like morphology, and T-cell-stimulating capability, we concluded that $\mathrm{CD} 14^{\mathrm{hi}} \mathrm{CD} 11 \mathrm{~b}{ }^{\mathrm{hi}}$ cells in the Flt $3 \mathrm{~L}^{-/-}$mouse lungs are likely functional moDCs, and that $F l t 3 \mathrm{~L}^{-/-}$mice are a useful genetic model for studying migratory and functional properties of moDCs in vivo. 
a

Lung DCs
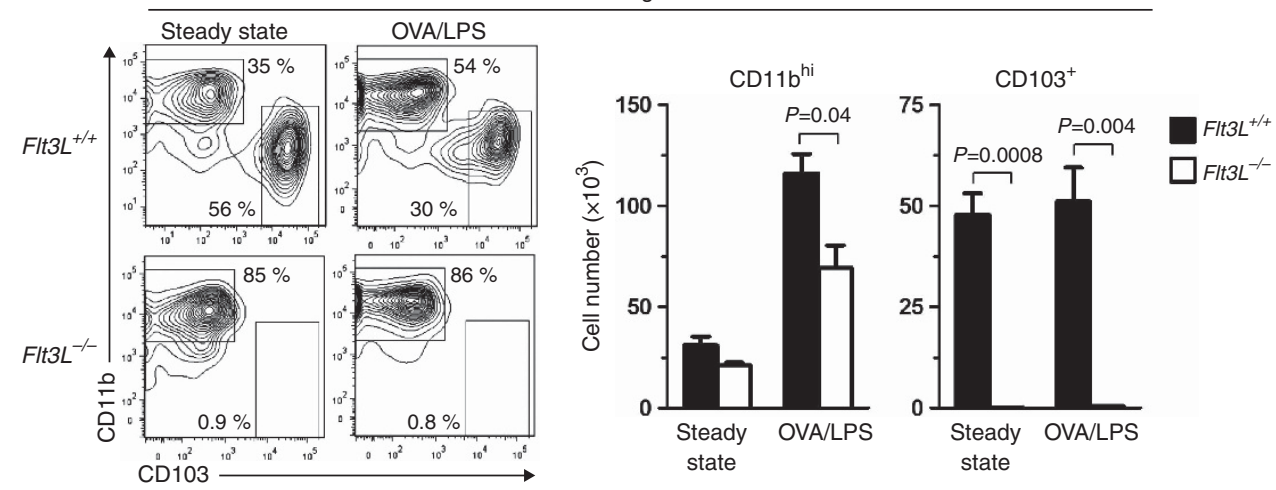

b

CD11b ${ }^{\text {hi }}$ DCs
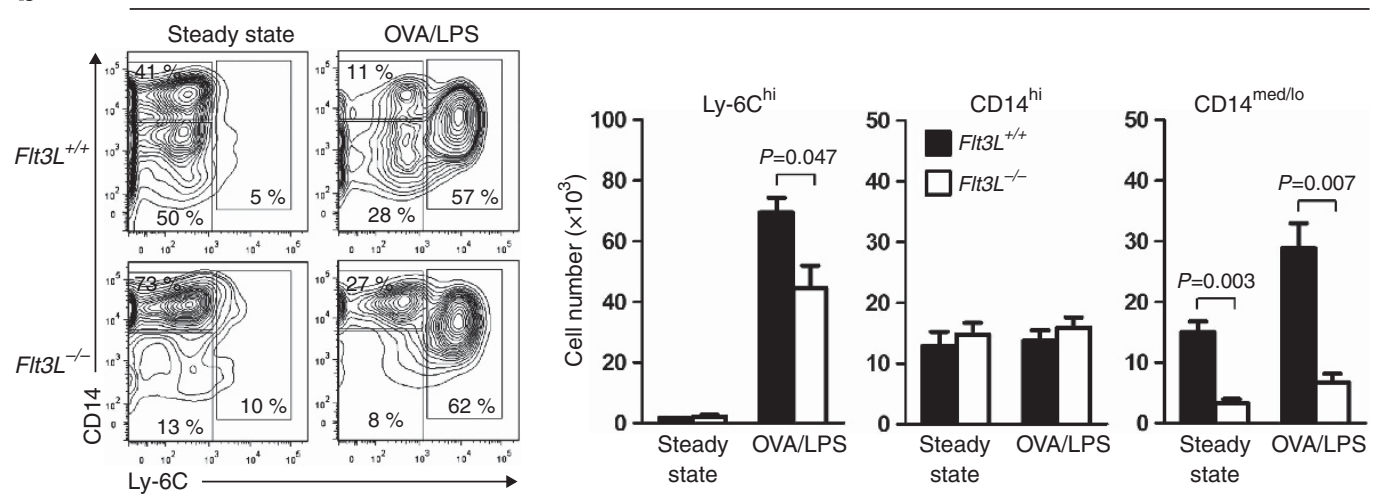

c

One day after monocyte transfer
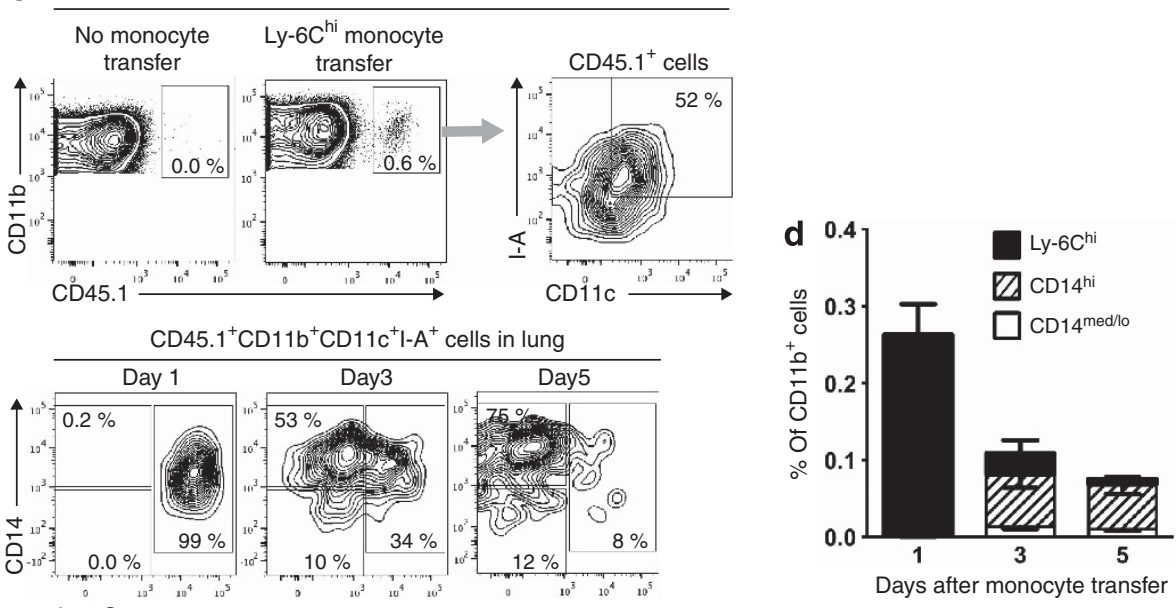

Figure 6 Ly-6C $\mathrm{Ch}^{\mathrm{hi}}$ and CD14 ${ }^{\mathrm{hi}}$ cells in CD11 $\mathrm{b}^{\text {hi }}$ dendritic cells (DCs) are monocyte-derived. (a) Analysis of major lung DC subsets in wild-type and Flt3L $L^{-/-}$ mice. Cytograms showing CD103 and CD11b staining of total CD11c ${ }^{+} I-A^{+}$lung DCs (left) and histograms of total, CD11 $b^{\text {hi }}$, and CD 103 ${ }^{+}$lung DCs under steady-state conditions and $16 \mathrm{~h}$ after ovalbumin/lipopolysaccharide (OVA/LPS) instillation (right) $(n=3)$. (b) Cytograms showing CD14 and Ly-6C staining of CD11 $\mathrm{b}^{\mathrm{hi}}$ lung DCs (left) and histograms of Ly- $6 C^{\text {hi }}, \mathrm{CD} 14^{\mathrm{hi}}$ and CD14 ${ }^{\mathrm{med} / \mathrm{lo}} \mathrm{DCs}$ under steady-state conditions and $16 \mathrm{~h}$ after OVA/LPS instillation (right) $(n=3)$. (c) Cytograms show gating of donor-derived DCs (CD45.1 ${ }^{+}$CD11 $b^{\text {hi }}$ CD11c ${ }^{+}$I-A ${ }^{+}$) (top), and display of CD14 and Ly-6C on those

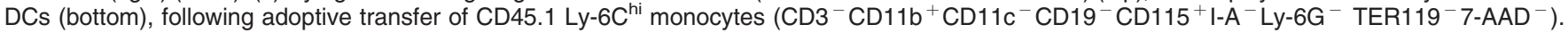
Recipient CD45.2 mice were instilled with OVA/LPS 2 hrs prior to the monocyte transfer. (d) Histograms showing the number of monocyte-derived DCs corresponding to the indicated populations $(n=3)$. A representative result of three independent experiments is shown.

Having confirmed that the CD $11 b^{\text {hi }}$ DCs in $\mathrm{Flt}_{3} \mathrm{~L}^{-/-}$mice are restricted to moDCs, we investigated Ccr7 expression in lung DCs in these animals. CD11b ${ }^{\text {hi }}$ DCs from Flt3 $L^{-/-}$mice did not express appreciable levels of Ccr7 mRNA (Figure 7a).
Moreover, whereas PKH-labeled CD11b ${ }^{\text {hi }}$ DCs from wildtype mice readily migrated to mLNs, CD $11 b^{\text {hi }}$ DCs counterparts from Flt3L $\mathrm{L}^{-/-}$mice did not, even when low$(0.1 \mu \mathrm{g})$ or high-dose $(10 \mu \mathrm{g})$ LPS (Figures $7 \mathbf{b}, \mathbf{c})$ was instilled to 

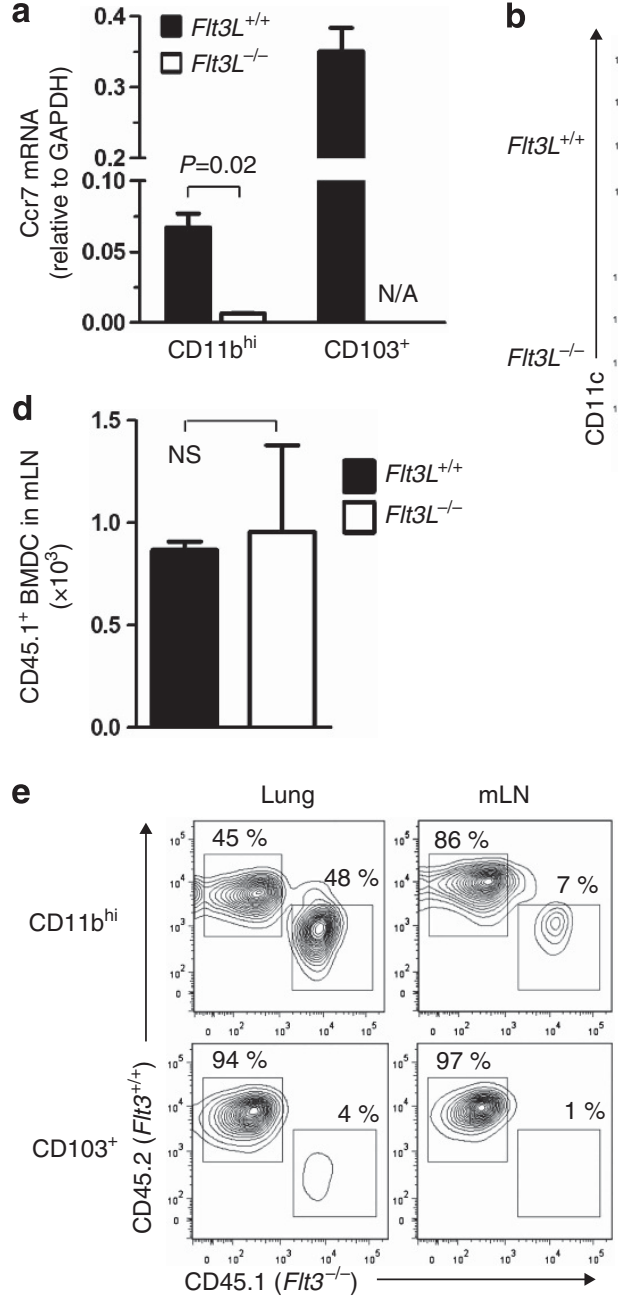
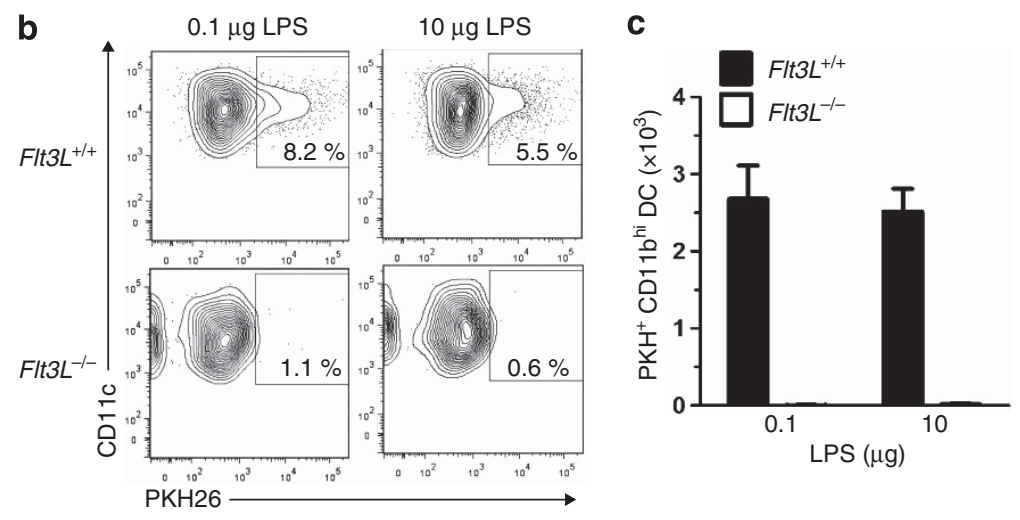

f

CD45.2 $\left(F / 3^{+/+}\right)$

$\square \mathrm{CD} 45.1\left(\mathrm{Flt3} 3^{--)}\right.$

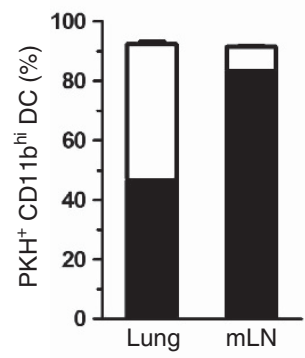

g

$\operatorname{CD} 45.2\left(F / 3^{+/+}\right)$ $\square \operatorname{CD} 45.1\left(\right.$ Flt3 $\left.{ }^{-1-}\right)$
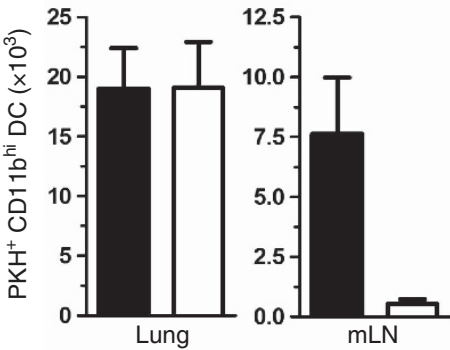
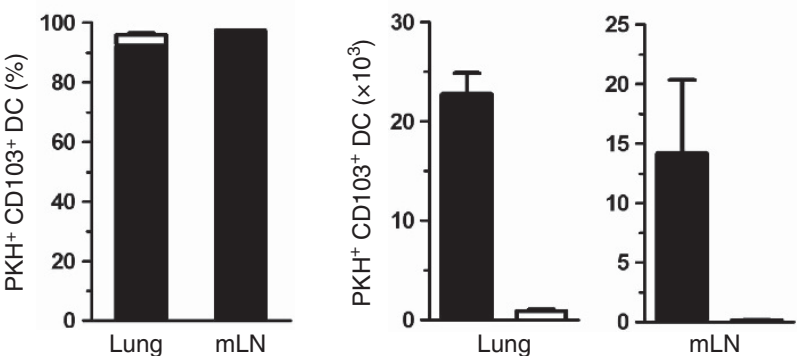

Figure 7 FLT3L/FLT3L-independent, monocyte-derived CD11 $\mathrm{b}^{\text {hi }}$ dendritic cells (DCs) are non-migratory. (a) Ccr7 mRNA levels in lung DC subsets of wild-type and Flt3L ${ }^{-1-}$ mice as measured by qPCR ( $n=2$ to 9$)$. (b, c) PKH ${ }^{+}$migratory CD $11 b^{\text {hi }}$ DCs in mediastinal lymph nodes (mLNs) $24 \mathrm{~h}$ after lipopolysaccharide (LPS) instillation into airways of wild-type and Flt3L ${ }^{-1}$ mice $(n=3)$. A representative result of two

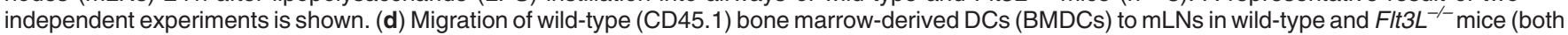
CD45.2) following airway instillation of the donor DCs followed by ovalbumin/LPS $4 \mathrm{~h}$ later. Analysis of $\mathrm{mLNs}$ from recipient mice was performed $20 \mathrm{~h}$ later by flow cytometry. (e-g) Migration assay of Flt3 ${ }^{-1-}$ DCs from lung to $\mathrm{mLNs}$. (e) Mixed BM chimeric mice were generated by transfer of a mixture of wildtype (CD45.2) and Flt3 ${ }^{-1-}$ (CD45.1) BM cells into irradiated wild-type (CD45.2) mice. Lung and $\mathrm{mLN}$ DCs in the recipients were analyzed $16 \mathrm{~h}$ after PKH instillation to airway. Flow plots of cells displaying CD45.1 or CD45.2 in PKH-gated CD11 bi and CD103 ${ }^{+}$DCs are shown. Percentage (f) and absolute number $(\mathrm{g})$ of $\mathrm{PKH}^{+}$wild-type and Flt3 ${ }^{-/-} \mathrm{DCs}$ in lung and $\mathrm{mLNs}$ of the chimeric mice. A representative result of two independent experiments is shown. GAPDH, glyceraldehyde 3-phosphate dehydrogenase; N/A, not applicable; NS, not significant.

induce inflammation. The virtual absence of $\mathrm{PKH}^{+}$migratory CD11bi $b^{\text {hi }}$ DCs in mLNs of Flt3L $L^{-/-}$mice was probably not related to unanticipated changes in the lymphatics or the LNs of these animals, because in vitro-generated wild-type BMDCs migrated from the airway to mLNs of Flt3L $\mathrm{L}^{-/-}$and wild-typerecipient mice with comparable efficiencies (Figure 7d). To confirm that FLT3/FLT3L interactions are required for the development of migratory DCs, we tested lung DC migration in chimeric mice in which wild-type mice received a mixture of BM from genetically marked wild-type (CD45.2) and Flt3 $3^{-/-}$ donor (CD45.1) mice. PKH was instilled into the airways of these chimeric mice so that we could follow migration of both types of donor-derived DCs to mLNs. As expected, $\mathrm{PKH}^{+}$
$\mathrm{CD}_{103}{ }^{+}$DCs in the lung and LNs of these chimeric mice were derived exclusively from wild-type (CD45.2) mice because FLT3 is required for the development of these cells (Figures 7e-g). By contrast, $\mathrm{PKH}^{+} \mathrm{CD} 11 \mathrm{~b}^{\text {hi }}$ DCs in the lungs of the chimeric mice were derived almost equally from wild-type and Flt3 ${ }^{-/-}$ donors. Despite that, almost all $\mathrm{PKH}^{+} \mathrm{CD}_{11 b^{\text {hi }}}$ DCs in mLNs of the chimeric mice were derived from wild-type donors. Thus, although $\mathrm{Flt3}^{-/-} \mathrm{CD} 1 \mathrm{bb}$ hi moDCs develop normally and accumulate in the lung, they do not readily migrate to mLNs. Based on these results, we conclude that in the lung, migratory DCs are comprised almost exclusively of FLT3- and FLT3L-dependent cDCs, and that FLT3- and FLT3Lindependent moDCs are intrinsically non-migratory. 


\section{DISCUSSION}

Lung-resident DCs are well-known to take up inhaled antigens and migrate to draining LNs for presentation of antigenderived peptides to naive $\mathrm{T}$ cells. However, in experimental models of asthma DCs are also required during the challenge phase, ${ }^{8,9}$ suggesting that some DCs have evolved to remain in the lung and activate antigen-specific memory cells recruited to the lung upon secondary exposure to antigens. For example, lung-resident DCs are required to trigger release of inflammatory mediators by influenza-specific $\mathrm{CD} 8{ }^{+} \mathrm{T}$ cells during the late phase of influenza infection, after most of the virus has been cleared. ${ }^{41}$ Thus, non-migratory, lung-resident DCs might provide important functions during recall responses to antigen challenge. If so, reducing or preventing the accumulation of these cells in the inflamed lung might diminish the pathological inflammation seen in these and other diseases.

It has been unclear whether the migration of individual DCs is stochastic, determined solely by exposure to pro-inflammatory stimuli or cytokines, or whether some DCs are programmed to remain in the lung. Resolving this issue should provide important clues to the primary functions of DC subsets. Our present findings reveal that in the lung, most cDCs, including $\mathrm{CD} 103^{+}$DCs and the $\mathrm{CD} 14^{\mathrm{med} / \mathrm{lo}}$ subset of CD $11 \mathrm{~b}^{\mathrm{hi}}$ DCs, are capable of expressing $\mathrm{Ccr} 7$ and migrating from the lung to mLNs, whereas moDCs do not express this receptor and do not migrate to draining LNs.

We found that compared with lung-resident $\mathrm{CD} 103^{+} \mathrm{DCs}$, fewer CD $11 b^{\text {hi }}$ DCs expressed Ccr7 after stimulation with LPS in vivo. This difference was largely due to the virtual absence of $\mathrm{Ccr} 7$ expression on the monocyte-derived subset of $\mathrm{CD} 11 \mathrm{~b}^{\mathrm{hi}}$ DCs. In fact, $\mathrm{CD} 14^{\mathrm{hi}}$ moDCs failed to express $C \mathrm{Cr} 7$, even after their purification from the lung and culture with LPScontaining media, whereas $\mathrm{C} c r 7$ was strongly increased under these conditions in $\mathrm{CD} 14{ }^{\mathrm{med} / \mathrm{lo}} \mathrm{CD} 11 \mathrm{~b}{ }^{\mathrm{hi}} \mathrm{cDCs}$ and in $\mathrm{CD} 103^{+}$ cDCs. This finding argues against the hypothesis that the inability of $\mathrm{CD} 14^{\mathrm{hi}}$ moDCs to increase $\mathrm{Ccr} 7$ expression is due solely to their anatomical positioning within the lung. Rather, our data suggest that the migratory properties of lung DCs are intrinsically programmed. Not all CD $11 \mathrm{~b}^{\text {hi }} \mathrm{cDCs}$ and $\mathrm{CD} 103^{+}$ cDCs were CCR7-GFP ${ }^{+}$after their overnight culture with LPScontaining media, but it is likely that $\mathrm{Ccr} 7$ expression had declined in some cells by the end of the culture period. This idea is supported by our finding that only half of $\mathrm{PKH}^{+}$migratory DCs in draining LNs were CCR7-GFP ${ }^{+}$, even though the migration of these cells is critically dependent on CCR7 and occurred during the $24 \mathrm{~h}$ between the labeling of these cells in the lung and their analysis in the LN. Thus, $\mathrm{Cr} r 7$ might be expressed only long enough to allow DC migration from the lung to T-cell zones in draining LNs.

Our present data suggest that the absence of $\mathrm{C} c \mathrm{r} 7$ expression in moDCs was not due solely to a lack of maturity because this receptor was absent not only in inflammatory DCs, but also in $\mathrm{CD} 14^{\text {hi }} \mathrm{CD} 11 \mathrm{~b}{ }^{\text {hi }}$ DCs in wild-type mice during steady-state conditions and in all CD11b ${ }^{\text {hi }}$ moDCs from Flt $3 L^{-/-}$mice. Apart from their levels of $\mathrm{Ccr} 7$ expression, the latter DCs appeared fully mature, as determined by their high display levels of MHC class II and co-stimulatory molecules, their DClike morphologies, and their ability to stimulate naive T-cell differentiation. Therefore, the absence of $\mathrm{Ccr} 7$ expression in moDCs is likely an intrinsic property of these cells and related to their descent from monocytes. The migratory differences between $C D 11 b^{\text {hi }}$ moDCs and CD11 bi ${ }^{\text {hi }}$ DCs might help to reconcile previous reports that came to different conclusions regarding the migratory properties of pulmonary CD11bi DCs. ${ }^{3,20,21,42,43}$ Although the signaling pathways that control $\mathrm{Ccr} 7$ expression are not yet well understood, a comparison of the transcriptional and epigenomic status of CD1 $1 b^{\text {hi }} \mathrm{cDCs}$ and moDCs will likely be informative in this regard.

Our finding that moDCs in the lung lack $C c r 7$ expression and are non-migratory is in apparent contrast with previous reports showing that moDCs can accumulate in LNs in a CCR7dependent manner upon systemic administration of LPS ${ }^{16}$ and that $\mathrm{Ccr} 7$ is expressed on Langerhans cells, ${ }^{44}$ which are monocyte-derived. ${ }^{45}$ We also confirmed that BM monocytes can differentiate into Ccr7-expressing DCs. Thus, not all moDCs lack Ccr7. It is possible that the microenvironment of the lung-and perhaps other tissues-provide signals that suppress $\mathrm{Ccr} 7$ expression in moDCs. Although in most cases the identities of such putative signals are unknown, there are several precedents for phenotypic differences among DCs of different tissues. For example, Langerhans cells are present only in the skin, and $\mathrm{CD} 103^{+} \mathrm{CD} 11 \mathrm{~b}^{+}$double-positive cells are found in large numbers in the lamina propria of the gut but are rare in the lung. ${ }^{13,28}$ Interestingly, these double-positive cells, which are $\mathrm{CX} 3 \mathrm{CR} 1^{-}$, express $\mathrm{Ccr} 7$ and migrate to gut-draining LNs, whereas $\mathrm{CD}_{103}{ }^{-} \mathrm{CX} 3 \mathrm{CR} 1^{+} \mathrm{DCs}$ in the lamina propria are non-migratory. ${ }^{28,46}$ To date, there have been no reports of $\mathrm{CD}_{103}{ }^{-} \mathrm{CD} 11 \mathrm{~b}^{\text {hi }}$ migratory $\mathrm{cDCs}$ in the gut that are similar to those that we have found in the lung. It is possible that the $\mathrm{CD}_{11 \mathrm{~b}}{ }^{+} \mathrm{CD}_{103}{ }^{+}$double-positive DCs in the gut are functionally analogous to $\mathrm{CD} 14^{\mathrm{med} / \mathrm{lo}} \mathrm{CD} 11 \mathrm{~b} \mathrm{bi}^{\text {hi }} \mathrm{cDC}$ in the lung, and that the phenotypic differences between these DC populations result from distinct signals provided by the different microenvironments in those organs. These observations imply that phenotypes of DCs are largely, but not entirely, determined during lineage differentiation. Identification of molecular signals in non-lymphoid tissue that act to fine tune functions of DCs will likely be an important area of future research in DC biology.

\section{METHODS}

Mice. C57BL/6, Crr $7^{-1}$, CD45.1 and OT-II TCR transgenic mice were purchased from Jackson Laboratories (Bar Harbor, ME). Flt $3 L^{-/-}$mice and control C57BL/6 mice were from Taconic (Germantown, NY). $C c r 7^{g f p}$ and $C c r 2^{-/-}$targeted insertion reporter mice on a C57BL/6 background were generated at Xenogen (Caliper Life Sciences, Hopkinton, MA) through a contractual arrangement with the NIEHS (see Supplementary Figures S2 and S3 online). Flt3 ${ }^{-1-}$ mice originally generated by Ihor Lemischka (Mount Sinai School of Medicine) were provided by Michel Nussenzweig (Rockefeller University). Mice were housed in specific pathogen-free conditions at the NIEHS or Rockefeller University and used between 6 and 12 weeks of age in accordance with guidelines provided by the Institutional Animal Care and Use Committees. 
Mouse sensitization and cell-tracker administration. Mice were anesthetized by isoflurane inhalation and given $100 \mu \mathrm{g}$ endotoxin-free OVA (Profos AG, Germany), alone or together with $0.1 \mu \mathrm{g}$ LPS (Sigma, St Louis, MO) or with $1 \mu \mathrm{g}$ poly (I:C) (InvivoGen, San Diego, CA) unless otherwise specified. Instillations of reagents were done by oropharyngeal aspiration as described previously. ${ }^{47}$ In some experiments, DCs were labeled in vivo by instillations of $50 \mu \mathrm{l}$ of $10 \mu \mathrm{m}$ PKH26 (Sigma) or CFSE (Invitrogen, Grand Island, NY) $24 \mathrm{~h}$ before OVA/LPS instillation unless specified. OVA-bearing DCs were identified by instillation of endotoxin-free OVA labeled with Alexa Fluor 647 (Invitrogen). For skin-draining DC analysis, $200 \mu \mathrm{l}$ phosphate-buffered saline containing $0.1 \mu \mathrm{g}$ LPS was injected into mouse tail veins $24 \mathrm{~h}$ before tissue harvest. To examine cell-tracker dye-induced airway inflammation, bronchoalveolar lavage was performed on mice $24 \mathrm{~h}$ after instillation of cell trackers, and the cells were counted under a microscope.

Preparation and analysis of pulmonary DCs. DCs from the mouse lungs and mLNs were prepared as described previously. ${ }^{13}$ Cells were diluted to $2 \times 10^{6} / 100 \mu \mathrm{l}$ and incubated with a non-specific-binding blocking reagent cocktail of anti-mouse CD16/CD32 (2.4G2), normal mouse, and rat serum (Jackson ImmunoResearch, West Grove, PA) for $5 \mathrm{~min}$. For staining of surface antigens, cells were incubated with fluorochrome (Allophycocyanin (APC), APC-Cy7, Alexa Fluor 488, Alexa Fluor 647, eFluor 450, eFluor 605 NC, FITC, PerCP-Cy5.5 or Phycoerythrin), or biotin-conjugated antibodies against mouse CD3 $\varepsilon$ (145-2C11), CD11b (M1/70), CD11c (N418 and HL3), CD14 (Sa2-8), CD19 (6D5), CD45.1 (A20), CD86 (GL1), CD103 (M290), CD115 (AFS98), CD117/c-Kit (2B8), CD197/CCR7 (4B12), Ly-6C (AL-21), Ly-6G (1A8), MHC class II I-A ${ }^{\mathrm{b}}$ (AFb.120), MMR (MR5D3) and Siglec-F (BD Biosciences (San Jose, CA), BioLegend (San Diego, CA) and eBioscience (San Diego, CA)). Staining with biotinylated antibodies was followed by fluorochrome-conjugated streptavidin. Stained cells were analyzed on a 5 laser LSRII, or sorted on a 5 laser ARIA-II flow cytometer (BD Biosciences), and the data analyzed using FACS Diva (BD Bioscience) and FlowJo software (Treestar, Ashland, OR). Dead cells were excluded based on their forward and side scatter. Only single cells were analyzed. In some experiments, DC subsets were purified and cultured in complete RPMI1640 (cRPMI) containing $100 \mathrm{ng} \mathrm{ml}^{-1}$ LPS (Sigma), in addition to $10 \%$ fetal bovine serum (Gemini, West Sacramento, CA), penicillin/streptomycin (InvitroGen) and $50 \mathrm{ng} \mathrm{ml}^{-1} \beta$-mercaptoethanol (Sigma). In some experiments, cells from purified subsets were centrifuged onto glass slides and photographed using an Olympus BX51 microscope, DP70 digital camera, and DP software (Olympus, Center Valley, PA).

Purification of monocytes and in vitro generation of DCs. Inflammatory monocytes $\left(\mathrm{CD} 3^{-} \mathrm{CD} 11 \mathrm{~b}^{+} \mathrm{CD} 19^{-} \mathrm{CD}_{4} 9 \mathrm{~b}^{-} \mathrm{I}^{-\mathrm{A}}{ }^{-} \mathrm{Ly}\right.$ -

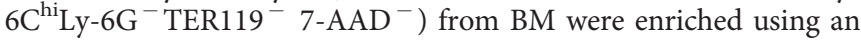
automated magnet-activated cell sorter (Miltenyi, Auburn, CA) and then further purified by flow cytometry-based sorting. To prepare BMDCs, marrow was collected, RBCs lysed with $0.15 \mathrm{M}$ ammonium chloride and $1 \mathrm{~mm}$ potassium bicarbonate, and the cells cultured in cRPMI containing $5 \mathrm{ng} \mathrm{ml}^{-1} \mathrm{GM}-\mathrm{CSF}$ (granulocyte macrophage colony-stimulating factor; R\&D Systems) for 9 days. To generate moDCs in vitro, purified BM monocytes were cultured in cRPMI containing $5 \mathrm{ng} \mathrm{ml}^{-1} \mathrm{GM}-\mathrm{CSF}$ and IL-4 (R\&D Systems). After 4 or 7 days of culture, cells were harvested and analyzed by flow cytometry or microscopy as described above.

BM chimera mice. $\mathrm{BM}$ chimeric mice were generated using a mixture of BM cells from C57BL/6 (CD45.2) and Flt3 ${ }^{-/-}$(CD45.1) mice at 4:6 ratio that was intravenously injected into tail veins of $9 \mathrm{~Gy} \gamma$-rayirradiated C57BL/6 mice $\left(10^{7}\right.$ cells/recipient) 6 weeks before experiment. $^{16}$

Adoptive transfer of cells. For BMDC migration assays, $10^{6}$ $\mathrm{CD}_{11 \mathrm{c}^{+}} \mathrm{I}-\mathrm{A}^{+}$DCs from CD $45.1^{+}$mice were instilled into airways of recipient $\mathrm{CD} 45.2^{+}$mice, and the efficiency of migration to $\mathrm{mLNs}$ assessed by quantitation of CD $45.1^{+}$donor DCs in mLNs. For monocyte fate studies, $6 \times 10^{5}$ purified monocytes were intravenously injected into mouse tail veins.

Co-culture of naive T cells with DCs. Naive CD4 ${ }^{+} \mathrm{T}$ cells were prepared from pools of LNs and spleens of OT-II TCR transgenic mice as previously described. ${ }^{13}$ DCs were purified by flow cytometric sorting $^{13}$ from the lungs of mice that had received OVA/LPS $16 \mathrm{~h}$ earlier. The OT-II T cells $\left(10^{5} /\right.$ well $)$ were cultured together with lung DCs $\left(5 \times 10^{4} /\right.$ well $)$ in a $5 \% \mathrm{CO}_{2}$ incubator in $200 \mu \mathrm{l}$ Iscove's modified Dulbecco's medium containing $10 \%$ fetal bovine serum (certified, Invitrogen), $50 \mu \mathrm{M} \beta$-mercaptoethanol, penicillin, and streptomycin in a 96-well U-bottom plate (BD Biosciences). After 5 days of the primary co-culture, T cells $\left(10^{5} /\right.$ well $)$ were transferred to a 96-well flat-bottomed plate coated with $1 \mu \mathrm{g} \mathrm{ml}^{-1}$ anti-CD3 $\varepsilon$ and $5 \mu \mathrm{g} \mathrm{ml}^{-1}$ anti-CD28 antibodies (eBioscience), and IFN- $\gamma$ or IL-13 in the cell supernatants were analyzed $24 \mathrm{~h}$ later by enzyme-linked immunosorbent assay as measures of Th1 and Th2 induction, respectively.

Quantitative PCR. Total RNA was isolated from sorted DCs using RNeasy kit (Qiagen, Valencia, CA) and converted to cDNA with oligo dT primers and SuperScript III First Strand kit (Invitrogen). PCR amplification was performed using TaqMan primers and probes (Applied Biosystems, Foster City, CA) for mouse Ccr7 (assay ID: Mm01301785_m1) and Gapdh (assay ID: Mm99999915_g1) with TaqMan PCR Master Mix (Applied Biosystems) and Mx3000P QPCR system (Agilent Technologies, Santa Clara, CA). The relative expression level of each gene was determined according to the manufacturer's instruction and normalized to Gapdh expression.

Statistics. Data are expressed as mean \pm s.e.m. Statistical differences between groups were calculated using a two-tailed Student's $t$-test, unless indicated otherwise. $P<0.05$ was considered significant.

SUPPLEMENTARY MATERIAL is linked to the online version of the paper at http://www.nature.com/mi

\section{ACKNOWLEDGEMENTS}

We thank Maria Sifre for help with flow cytometry, Ligon Perrow for support with animal experiments, and Michael Fessler and Kym Gowdy (NIEHS) for critical reading of the manuscript. This work was supported by the Intramural Research Program of the National Institutes of Health and the National Institute of Environmental Health Sciences.

\section{DISCLOSURE}

The authors declared no conflict of interest.

c) 2013 Society for Mucosal Immunology

\section{REFERENCES}

1. Steinman, R.M. Lasker Basic Medical Research Award. Dendritic cells: versatile controllers of the immune system. Nat. Med. 13, 1155-1159 (2007).

2. Lambrecht, B.N. \& Hammad, H. Lung dendritic cells in respiratory viral infection and asthma: from protection to immunopathology. Annu. Rev. Immunol. 30, 243-270 (2012).

3. Jakubzick, C. et al. Lymph-migrating, tissue-derived dendritic cells are minor constituents within steady-state lymph nodes. J. Exp. Med. 205, 2839-2850 (2008).

4. Vermaelen, K.Y., Carro-Muino, I., Lambrecht, B.N. \& Pauwels, R.A. Specific migratory dendritic cells rapidly transport antigen from the airways to the thoracic lymph nodes. J. Exp. Med. 193, 51-60 (2001).

5. Desch, A.N. et al. CD103 + pulmonary dendritic cells preferentially acquire and present apoptotic cell-associated antigen. J. Exp. Med. 208, 17891797 (2011). 
6. Julia, V. et al. A restricted subset of dendritic cells captures airborne antigens and remains able to activate specific T cells long after antigen exposure. Immunity 16, 271-283 (2002).

7. GeurtsvanKessel, C.H et al. Dendritic cells are crucial for maintenance of tertiary lymphoid structures in the lung of influenza virus-infected mice. J. Exp. Med. 206, 2339-2349 (2009).

8. Lambrecht, B.N., Salomon, B., Klatzmann, D. \& Pauwels, R.A. Dendritic cells are required for the development of chronic eosinophilic airway inflammation in response to inhaled antigen in sensitized mice. J. Immunol. 160, 4090-4097 (1998).

9. van Rijt, L.S. et al. In vivo depletion of lung CD11c + dendritic cells during allergen challenge abrogates the characteristic features of asthma. J. Exp. Med. 201, 981-991 (2005).

10. Sung, S.S. et al. A major lung CD103 (alphaE)-beta7 integrin-positive epithelial dendritic cell population expressing Langerin and tight junction proteins. J. Immunol. 176, 2161-2172 (2006).

11. del Rio, M.L., Rodriguez-Barbosa, J.I., Kremmer, E. \& Forster, R. CD103and CD103 + bronchial lymph node dendritic cells are specialized in presenting and cross-presenting innocuous antigen to CD4 + and CD8 + T cells. J. Immunol. 178, 6861-6866 (2007).

12. GeurtsvanKessel, C.H. et al. Clearance of influenza virus from the lung depends on migratory langerin $+\mathrm{CD} 11 \mathrm{~b}$ - but not plasmacytoid dendritic cells. J. Exp. Med. 205, 1621-1634 (2008).

13. Nakano, $H$. et al. Pulmonary CD103(+) dendritic cells prime Th2 responses to inhaled allergens. Mucosal Immunol. 5, 53-65 (2012).

14. Beaty, S.R., Rose, C.E. Jr. \& Sung, S.S. Diverse and potent chemokine production by lung CD11bhigh dendritic cells in homeostasis and in allergic lung inflammation. J. Immunol. 178, 1882-1895 (2007).

15. Lin, K.L., Suzuki, Y., Nakano, H., Ramsburg, E. \& Gunn, M.D. CCR2 + monocyte-derived dendritic cells and exudate macrophages produce influenza-induced pulmonary immune pathology and mortality. J. Immunol. 180, 2562-2572 (2008).

16. Cheong, C. et al. Microbial stimulation fully differentiates monocytes to DCSIGN/CD209(+) dendritic cells for immune Tcell areas. Cell 143, 416-429 (2010).

17. Forster, R. et al. CCR7 coordinates the primary immune response by establishing functional microenvironments in secondary lymphoid organs. Cell 99, 23-33 (1999).

18. Gunn, M.D. et al. Mice lacking expression of secondary lymphoid organ chemokine have defects in lymphocyte homing and dendritic cell localization. J. Exp. Med. 189, 451-460 (1999).

19. Gunn, M.D., Tangemann, K., Tam, C., Cyster, J.G., Rosen, S.D. \& William, L.T et al. A chemokine expressed in lymphoid high endothelial venules promotes the adhesion and chemotaxis of naive $\mathrm{T}$ lymphocytes. Proc. Natl. Acad. Sci. Usa 95, 258-263 (1998).

20. Hintzen, G. et al. Induction of tolerance to innocuous inhaled antigen relies on a CCR7-dependent dendritic cell-mediated antigen transport to the bronchial lymph node. J. Immunol. 177, 7346-7354 (2006).

21. Jakubzick, C., Tacke, F., Llodra, J., van Rooijen, N. \& Randolph, G.J. Modulation of dendritic cell trafficking to and from the airways. J. Immunol. 176, 3578-3584 (2006).

22. Raymond, M. et al. Selective control of SIRP-alpha-positive airway dendritic cell trafficking through CD47 is critical for the development of $\mathrm{T}(\mathrm{H}) 2$-mediated allergic inflammation. J. Allergy. Clin. Immunol. 124, 1333-1342. e1331 (2009).

23. Fogg, D.K. et al. A clonogenic bone marrow progenitor specific for macrophages and dendritic cells. Science 311, 83-87 (2006).

24. Varol, C. et al. Monocytes give rise to mucosal, but not splenic, conventional dendritic cells. J. Exp. Med. 204, 171-180 (2007).

25. Naik, S.H. et al. Development of plasmacytoid and conventional dendritic cell subtypes from single precursor cells derived in vitro and in vivo. Nat. Immunol. 8, 1217-1226 (2007).
26. Onai, N. et al. Identification of clonogenic common Flt3 + M-CSFR + plasmacytoid and conventional dendritic cell progenitors in mouse bone marrow. Nat. Immunol. 8, 1207-1216 (2007).

27. Ginhoux, F. et al. The origin and development of nonlymphoid tissue CD103 + DCs. J. Exp. Med. 206, 3115-3130 (2009).

28. Bogunovic, M. et al. Origin of the lamina propria dendritic cell network. Immunity 31, 513-525 (2009).

29. Geissmann, F., Jung, S. \& Littman, D.R. Blood monocytes consist of two principal subsets with distinct migratory properties. Immunity 19, 71-82 (2003).

30. Landsman, L., Varol, C. \& Jung, S. Distinct differentiation potential of blood monocyte subsets in the lung. J. Immunol. 178, 2000-2007 (2007).

31. Jakubzick, C. \& Randolph, G.J. Methods to study pulmonary dendritic cell migration. Methods Mol. Biol. 595, 371-382 (2010).

32. Stevens, W.W., Kim, T.S., Pujanauski, L.M., Hao, X. \& Braciale, T.J. Detection and quantitation of eosinophils in the murine respiratory tract by flow cytometry. J. Immunol. Methods 327, 63-74 (2007).

33. Vermaelen, K. \& Pauwels, R. Accurate and simple discrimination of mouse pulmonary dendritic cell and macrophage populations by flow cytometry: methodology and new insights. Cytometry 61, 170-177 (2004).

34. Eisenbarth, S.C. et al. Lipopolysaccharide-enhanced, toll-like receptor 4dependent Thelper cell type 2 responses to inhaled antigen. J. Exp. Med. 196, 1645-1651 (2002).

35. Jakubzick, C., Helft, J., Kaplan, T.J. \& Randolph, G.J. Optimization of methods to study pulmonary dendritic cell migration reveals distinct capacities of DC subsets to acquire soluble versus particulate antigen. J. Immunol. Methods 337, 121-131 (2008).

36. Horan, P.K., Melnicoff, M.J., Jensen, B.D. \& Slezak, S.E. Fluorescent cell labeling for in vivo and in vitro cell tracking. Methods Cell Biol. 33, 469-490 (1990).

37. Nakano, H. etal. Blood-derived inflammatory dendritic cells in lymph nodes stimulate acute Thelper type 1 immune responses. Nat. Immunol. 10, 394 402 (2009).

38. Leon, B., Lopez-Bravo, M. \& Ardavin, C. Monocyte-derived dendritic cells formed at the infection site control the induction of protective T helper 1 responses against Leishmania. Immunity 26, 519-531 (2007).

39. Serbina, N.V. \& Pamer, E.G. Monocyte emigration from bone marrow during bacterial infection requires signals mediated by chemokine receptor CCR2. Nat. Immunol. 7, 311-317 (2006).

40. Waskow, C. et al. The receptor tyrosine kinase Flt3 is required for dendritic cell development in peripheral lymphoid tissues. Nat. Immunol. 9, 676-683 (2008).

41. Hufford, M.M., Kim, T.S., Sun, J. \& Braciale, T.J. Antiviral CD8 + T cell effector activities in situ are regulated by target cell type. J. Exp. Med. 208, 167-180 (2011).

42. Belz, G.T et al. Distinct migrating and nonmigrating dendritic cell populations are involved in $\mathrm{MHC}$ class I-restricted antigen presentation after lung infection with virus. Proc. Natl. Acad. Sci. USA 101, 8670-8675 (2004).

43. Lukens, M.V., Kruijsen, D., Coenjaerts, F.E., Kimpen, J.L. \& van Bleek, G.M. Respiratory syncytial virus-induced activation and migration of respiratory dendritic cells and subsequent antigen presentation in the lung-draining lymph node. J. Virol. 83, 7235-7243 (2009).

44. Ohl, L. etal. CCR7 governs skin dendritic cell migration under inflammatory and steady-state conditions. Immunity 21, 279-288 (2004).

45. Merad, M. et al. Langerhans cells renew in the skin throughout life under steady-state conditions. Nat. Immunol. 3, 1135-1141 (2002).

46. Schulz, O. et al. Intestinal CD103 +, but not CX3CR1 + , antigen sampling cells migrate in lymph and serve classical dendritic cell functions. J. Exp. Med. 206, 3101-3114 (2009).

47. Wilson, R.H. et al. Allergic sensitization through the airway primes Th17dependent neutrophilia and airway hyperresponsiveness. Am. J. Respir. Crit. Care Med. 180, 720-730 (2009). 